\title{
Review of Alberta Environment's Ecosystem Goods and Services Assessment - Southern Alberta Phase 2 Report
}

Prepared for

Alberta Environment

August 2007

Prepared by

Management and Solutions in Environmental Science

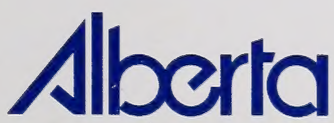

Environment 


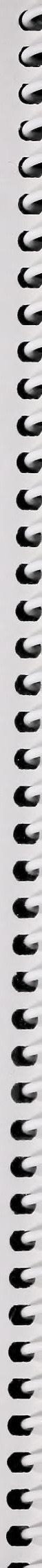


ISBN: 978-0-7785-6792-9 (Print version)

ISBN: 978-0-7785-6793-6 (Online version)

Website: www.gov.ab.ca/env/

Disclaimer: The contents of this document have been prepared with funds from Alberta Environment but do not necessarily reflect the Ministry's views or policies. Any mention of trade names or commercial products does not constitute an endorsement or recommendation for use.

Any comments, questions or suggestions on the content of this document may be directed to:

Regional Environmental Management

Alberta Environment

3rd Floor, Deerfoot Square

2938 - II Street N. E.

Calgary, Alberta T2E 7L7

$\mathrm{Ph}:$ (403) 297-7602

Fx: (403) 297-6069

Additional copies of this document are available from:

Information Centre

Alberta Environment

Main Floor, Oxbridge Place

9820-106 Street

Edmonton, Alberta T5K 2J6

Ph: (780) 427-2700

Fx: (780) 422-4086

Outside of Edmonton dial 310-0000 for toll-free connection

Email: env.infocent@gov.ab.ca 
Copyright in this publication, regardless of format, belongs to Her Majesty the Queen in right of the Province of Alberta. Reproduction of this publication, in whole or in part, regardless of purpose, requires the prior written permission of Alberta Environment.

(c) Her Majesty the Queen in right of the Province of Alberta, 2007. 


\section{List of Contributors}

Wildlife Ecology \& Biodiversity

Community-based Conservation \&

Biodiversity Economics

Hydrology, GIS \& Remote Sensing

Terrestrial \& Landscape Ecology

Senior Review

Report Integration \&

Wildlife Ecology
Dr. Troy Whidden, P.Biol.

Dr. Kashif Sheikh, P. Biol.

Dr. Stefan Kienzle

Dr. Petr Komers, P.Biol.

Dr. Elizabeth Dickson, P.Biol.

Ms. Shannon Gavin, P.Biol. 


\section{Executive Summary}

Alberta Environment (AENV) requested that Management and Solutions in Environmental Science (MSES) review and assess their Ecosystem Goods and Services Assessment Report (EGS Assessment). The peer review provides comments on the main elements of the EGS Assessment. We base our review on the stated goal of the Ecosystem Services Project, namely that the "ultimate aim is ... to deliver the right information to policy developers and decision makers...". Specifically, MSES evaluates the overall framework of the EGS Assessment, addresses the questions posed by AENV, and provides recommendations for further discussion.

The following overarching comments or points are made on the EGS Assessment. More detailed responses to specific questions can be found in the body of our report. A list of recommendations for consideration is also provided.

I. The EGS Assessment presents a useful framework for assessing goods and services that are provided by landscape parameters, which are composed of a mosaic of habitats and a diversity of wildlife that uses them. However, for discussion we would like to highlight the anchoring question of this work: "How do ecosystem services support the maintenance of natural and anthropogenic assets?" . A service supporting an asset is only meaningful from an anthropogenic economic perspective, wherein a service is maintained strictly for its value to humans. From a natural ecosystem perspective, is it not the asset that supports the service rather than the other way around? The wording of the question has a major impact on how one views the direction of dependencies. The way that all spreadsheet tables are set up in the document suggests that a service maintains an asset. Using a cow and produced milk as an example, the milk is the result of the condition of the cow: no cow - no milk; poor cow - little milk; good cow - plenty of milk. The authors of the report ask questions from an economic perspective (translated): how does the milk support the maintenance of the cow? Therefore, all spreadsheet tables must be read from assets to services. However, ecological systems include parameters that may or may not fit neatly into human economic systems. For example, "How do Prairie Wetlands maintain the service of water regulation?" While sometimes there are feedbacks from the services to the assets, this important point of critique has a large impact on the overall assessment. In addition to summing-up and reporting the services, the values of the assets (which, in part, should consider asset condition) should be summed-up also.

2. The world's ecosystem services have been under-valued by several orders of magnitude. Many current economists' approaches to put dollar values to natural assets are highly inadequate. Civilizations died out (e.g. Sumerians in Mesopotamia) because one single element of the 
ecosystem (soil) was degraded (salinization) to such an extent that food production was severely decimated. In the given example, what was the value of the soil? Is the value of the soil in this example not close to infinite? This idea is corroborated by Costanza et al. (1997), who state that in one sense the total value of ecosystem services to the economy is infinite.

3. In addition to the problem of evaluating an economic service provided by natural assets, there is an emotional or spiritual service that is extremely difficult to express in monetary terms; the human perception of well-being provided by the surroundings. For example, what would the quality of our lives be without rivers and lakes? Or with only polluted rivers and lakes? Natural assets provide services that we need for our spiritual survival as a whole.

4. While the authors have undertaken a literature review (200 titles), it is not necessarily exhaustive. It is likely that there are many more publications that could be reviewed with potential findings that could be incorporated into the southern Alberta EGS Assessment framework. The EGS Assessment is very important and complex, and additional work is required to fill in many of the existing gaps.

5. One of the objectives of the assessment is to "Provide an understanding of the value of high quality ecosystems in relation to economic production in southern Alberta,..."(pg 5). Figure 3-I of the report (pg 12) presents a conceptual framework of the function of ecosystem services. However, the figure does not carry a clear message, as it does not provide specific details or an explanation of the different types of arrows. No other framework of value assessment of ecosystems is provided. De Groot et al. (2002) in Barg and Swanson (2004) provide one such figure (see Figure I, this report) that could be used as a starting point for the framework (written for Agriculture and Agri-Food Canada). A clear division of ecological, socio-cultural and economic values could facilitate the value assessment of ecosystem services in southern Alberta. 


\section{TABLE OF CONTENTS}

PAGE

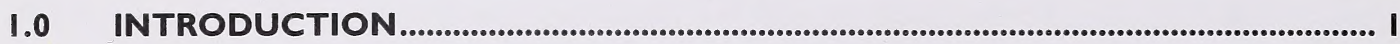

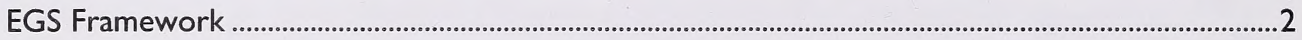

I.I.I Fundamentals of EGS..............................................................................................

I.I.2 How Much is an Ecosystem Worth? .............................................................................

I.I.3 Economic Valuation, Biodiversity and EGS.....................................................................

2.0 REVIEW QUESTIONS..................................................................................................... 4

2.I Evaluate the overall framework................................................................................................4

2.2 Review the relationships .......................................................................................................

2.3 Offer Additional Perspective ............................................................................................ 12

$2.4 \quad$ Respond to the following key questions …………………………………………………..... 15

3.0 ADDITIONAL DISCUSSION HIGHLIGHTS............................................................... 25

3.1 Comments on EGS Assessment Gap Analysis........................................................................ 26

3.2 Management Challenges of the Current EGS ............................................................................ 26

3.3 How Can this Program become more Meaningful?..................................................................... 27

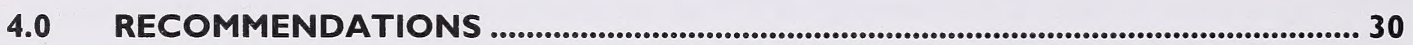

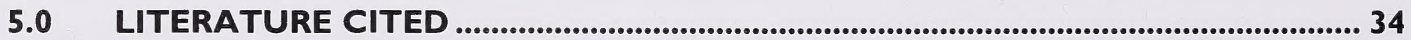


TABLE OF CONTENTS (cont)

PAGE

\section{LIST OF FIGURES}

Figure 1: A framework for integrated assessment and valuation of ecosystem functions, goods and services (from De Groot et al. (2002) in Barg and Swanson (2004) written for Agriculture and Agri-Food Canada). 8

\section{LIST OF APPENDICES}

Appendix A: Individual Review Reports 


\section{I.0 Introduction}

Alberta Environment (AENV) requested that Management and Solutions in Environmental Science (MSES) review and assess their Ecosystem Goods and Services Assessment Phase 2 Report (EGS Assessment). The overall purpose of the EGS Assessment is to identify "what EGS are important to southern Alberta and how they are key in sustaining the region's vibrant economy and quality of life" (pg 3). The EGS Assessment is intended to lend support to the Southern Alberta Landscapes (SAL) regional strategy that will provide a foundation for environmental and resource management in that area. The objectives of the EGS Assessment in southern Alberta are to:

- Inform people about ecosystem goods and services and how they are important to economic production in southern Alberta,

- Help people understand how land use decisions and human activities impact these services,

- Determine what landscape patterns are required to sustain the ongoing delivery of ecosystem goods and services, and

- Undertake a gap analysis to identify directions for further study and investigation.

Our peer review provides comments on the main elements of the EGS Assessment. We based our review on the stated goal of the Ecosystem Services Project, namely that the "ultimate aim is ... to deliver the right information to policy developers and decision makers...". Specifically, MSES evaluated the overall framework of the EGS Assessment, addressed the specific questions posed by AENV representatives, and provided recommendations for further discussion. The documents reviewed include:

- Ecosystems Good and Services Report- Southern Alberta Phase I Report: Key Actors and Initiatives

- Ecosystems Good and Services Report- Southern Alberta Phase 2 Report: Conceptual Linkages and Initial Assessment

In addition, on 28 August 2007, MSES met with members of the EGS Assessment team from Integrated Environments (2006) Ltd and O2 Planning + Design Inc to discuss their approach to the project and to solicit informal feedback on questions raised by the MSES review team. 


\section{EGS Framework}

The Convention of Biological Diversity (CBD) is considered the mother of international biodiversity conservation and sustainable development. It has a huge emphasis on the ecosystem approach and on landscape management at the ecosystem level. Article 2 of the CBD defines ecosystem as "a dynamic complex of plant, animal and micro-organism communities and their non-living environment interacting as a functional unit".

At the international level, the importance of biodiversity and ecosystem services to human wellbeing has been enshrined in the text of several multilateral environmental agreements. For example, the preamble to the CBD notes "the intrinsic value of biological diversity and of the ecological, genetic, social, economic, scientific, educational, cultural, recreational and aesthetic values of biological diversity and its components". In addition, the Convention on International Trade in Endangered Species of Wild Fauna and Flora (CITES) is "Conscious of the ever-growing value of wild fauna and flora from aesthetic, scientific, cultural, recreational and economic points of view".

\section{I.I.I Fundamentals of EGS}

The ecosystem approach is a strategy for the integrated management of land, water and living resources that promotes conservation and sustainable use in an equitable way. Application of the ecosystem approach will help to reach a balance of the three objectives of the CBD:

I. Conservation of biodiversity;

2. Sustainable use of biodiversity; and

3. Sharing of equitable benefits arising from the sustainable use of biodiversity.

The ecosystem approach is based on the application of appropriate scientific methodologies focused on levels of biological organization which encompass the essential processes, functions and interactions among organisms and their environment. It recognizes that humans, with their cultural diversity, are an integral component of ecosystems. Keeping these concepts in mind, we need an integrated approach to science that gets the public involved discussing the significance of scientific findings before advice goes to the policy and decision makers. Initial involvement of public and other key stakeholders can provide key insights into the functioning and limitation of an ecosystem and could put the assessment processes many steps ahead. In summary, an integrated EGS assessment may ensure: 
- Wider stakeholder involvement, helpful to generate long-term effective partnerships and effective conservation decision making for long-term sustainability of wild resources.

- No compromise on species, habitats and ecosystems declared threatened or endangered.

- Use of appropriate spatial analysis of all components and levels of an ecosystem.

- Economic valuation of the major assets, goods and services generated from the subject ecosystem.

- Reasonable linkages with public policy dialogues and environmental friendly business or trade for effective, but sustainable environmental decision making.

\section{I.I.2 How Much is an Ecosystem Worth?}

Ecosystems provide a wide variety of useful services that enhance human well-being. Ecosystem services are defined as "the benefits of nature to households, communities, and economies." The term has gained currency because it conveys an important idea that ecosystems are socially valuable, in ways that may not be immediately intuited (Daily 1997). The degradation of ecosystem services, even falling well short of outright destruction, would significantly affect our welfare. It has often been argued that a major reason for our failure to conserve natural ecosystems is that we do not realize how valuable they are. The farmers deciding whether to burn a forest clear for agriculture focus on the potential crop yields they may obtain, paying little attention to the many ecological services that would be destroyed. Likewise, national ministers of finance often base their budget decisions solely on the basis of indicators such as GDP, foreign exchange balances, and tax receipts, in which ecosystems services either do not appear or are not recognized as valuable. Indeed, perversely, GDP often identifies activities that destroy ecosystems as 'benefits'. Not surprisingly, conservation budgets tend to get slighted (IUCN, The Nature Conservancy and The World Bank 2004).

\section{I.I.3 Economic Valuation, Biodiversity and EGS}

An ecosystem is a dynamic complex of plants, animals, micro-organisms and non-living components interacting as a functional unit. Ecosystems provide a wide range of services through bio-geo-chemical processes that are critical for sustaining, strengthening and enriching various constituents of human wellbeing. Human well-being here refers to a holistic set of basic material for a good life, freedom to act and make choices, good social relations, and security (Millennium Ecosystem Assessment 2003). The unique feature of most of the services emanating from ecosystems is that, although acknowledged by people, they either are unaccounted for or are without a market value and therefore, remain outside the domain of the market. In particular, the value of maintaining biodiversity has not been adequately addressed: e.g. maintaining the diversity of ecosystems within a landscape, the diversity of species within an ecosystem, and the diversity of genes within a population. In conventional phrasing, such problems 
are treated as externalities where the market fails, and decision makers try to correct the market failure by creating a market-like situation. Subsequently they obtain the value of services through various valuation techniques based on the stated preferences of the people. In the case of the regulating services of ecosystems, like climate regulation, waste treatment capacity, nutrient management and various watershed functions, classic examples of market failure appears (Bator 1958).

Economic valuation is one of the tools we can use to assess the benefits of ecosystem conservation as well as how these benefits are distributed among the stakeholders. Through an analysis of benefits and costs, we can begin to understand some of the forces which may be threatening the existence of an ecosystem. A major threat to conserving ecosystems, including forest, savannah and wetland systems, is the demand to use the land for agricultural or ranching purposes (Vorhies 2003). By recognizing the benefits and costs facing local communities from conserving the ecosystem, we will be able to reduce the pressures and boost the substantial returns from ecosystem conservation.

\subsection{Review Questions}

The following questions were provided to MSES by AENV representatives to use as a guide in the review of the EGS Assessment. Each individual reviewer responded to this specific set of questions (see Appendix A). We have condensed and merged their responses below.

\section{I Evaluate the overall framework}

Question: Evaluate the overall framework developed to highlight the relationships between the goods, services and assets and rank the importance of ecosystem services in southern Alberta.

\section{Discussion Point I}

The EGS Assessment presents a useful framework for assessing goods and services that are provided by landscape parameters, which are composed of a mosaic of habitats and a diversity of wildlife that uses them. However, for discussion we would like to highlight the anchoring question in this work: "How do ecosystem services support the maintenance of natural and anthropogenic assets?" A service supporting an asset is only meaningful from an anthropogenic economic perspective, wherein a service is maintained strictly for its value to humans. From a natural ecosystem perspective, is it not the asset that supports the service rather than the other way around? The wording of the question has a major impact on how one views the direction of dependencies. The way all spreadsheet tables are set up in the document suggests that a service maintains an asset. Using a cow and produced milk as an example, the milk is the result of the condition of the cow: no cow - no milk, poor cow - little milk, good cow - plenty of milk. The authors of the report ask from an economic perspective (translated): how does the milk support 
the maintenance of the cow? Therefore, all spreadsheet tables must be read from assets to services. However, ecological systems include parameters that may or may not fit neatly into human economic systems. For example, "How do Prairie Wetlands maintain the service of water regulation?" While sometimes there are feedbacks from the services to the assets, this important point of critique has a large impact on the overall assessment. In addition to summing-up and reporting the services, the values of the assets (which, in part, should consider asset condition) should be summed-up also.

In the above line of thinking, one would evaluate the condition of the asset which then would translate into the quality of the service that the asset delivers. One can easily see that a fragmented forest would provide less, for example, gas regulation or water retention, than an intact large tract of forest. We agree with the point raised by the authors that "there is a direct, although not always linear, relationship between the condition of natural assets and the type, quantity and quality of services they provide" (pg 60). This is an important recognition for decision makers, namely that the degradation of a service can increase exponentially with the degradation of an asset.

Of course, knowledge of asset condition is paramount to the ultimate aim of the EGS Assessment in delivering the right information to policy developers and decision makers. Although Section 4.4 of the EGS Assessment provides a useful generalized approach to evaluating asset conditions, a great deal of work needs to be done before the ultimate aim of the EGS Assessment will be reached. This work would involve the landscape-scale measurement of composition, connectivity, and configuration, but it would also involve the evaluation of the asset components themselves, such as vegetation composition and wildlife population viability. In general terms, we assume that asset condition affects relative importance. From an ecological management point of view, the importance of an asset can increase with declining condition. For example, species (or habitats) that are rare are deemed important by resource managers. The highest importance is given to the most endangered species and habitats. As well, the amount of effort (in terms of time and money) that people are willing to invest into either experiencing or protecting an endangered species increases with the relative degree of endangerment. It follows that the value of an asset is determined by both the asset condition and the importance that people assign to the asset (there are many more aspects of how people may assign a value to wildlife assets which should be discussed elsewhere). This leads to the question of economic value (and, in turn, ecological value) which was indirectly used as the anchor for the EGA Assessment (line 3 on page 3). We discuss an alternative perspective on the framework of economic valuation as a tool for achieving the ultimate aim of the EGS Assessment within Section 2.3.

\section{Discussion Point 2}

"The importance of the world's ecosystem services is substantial. Costanza et al. (1997) estimated their value at US\$33 trillion per year, about I.8 times current global gross national product (GNP)" (Pg I). Costanza et 
al. (1997) further state "The services of ecological systems and the natural capital stocks that produce them are critical to the functioning of the Earth's life-support system. They contribute to human welfare, both directly and indirectly, and therefore represent part of the total economic value of the planet."

If one relates the above value of ecosystems services to the global population (assuming 6 billion), then everything supporting our lives (air, water, soil, plants, landscapes, food, materials, etc.) is valued at US\$ 5,500 per person per annum. Is this considered to be the value of a human being? Furthermore, if one were to take away any one of the services provided by a natural asset, either water or air or soil or plants, then no life could survive.

It appears that the value of the world's ecosystem services has been under-valued by several orders of magnitude. This demonstrates how inadequate are many current economists' approaches to putting dollar values to natural assets. Civilizations died out (e.g. Sumerians in Mesopotamia) because one single element of the ecosystem (soil) was degraded (salinization) to such an extent that food production was severely decimated. In the given example, what was the value of the soil? Isn't the value of soil in this example close to infinite? This concept is corroborated by Costanza et al. (1997), who state that in one sense, the total value of ecosystem services to the economy is infinite.

In addition to the problem of evaluating an economic service provided by natural assets, there is an emotional or spiritual service that is extremely difficult to express in monetary terms; the human perception of well-being provided by the surroundings. For example, what would the quality of our lives be without rivers and lakes? Or with only polluted rivers and lakes? Natural assets provide services that we need for our spiritual survival as a whole.

Costanza (2000) suggests three types of value systems that are relevant to the problem of evaluating ecosystems services, which are efficiency-based values (self interest, economical view point), fairnessbased value (community view point), and sustainability based value (science-based holistic ecological view point). Each view point has different requirements in terms of required discussion levels, the level of scientific input, and scientific methods. The sustainability value basis is based, according to Costanza (2000) on scientific modelling with precaution. For the evaluation of water resources impacts under a variety of conditions, for example land use change, or climate change, or projected economical growth scenarios, complex and physically-based hydrological models are available.

\section{Discussion Point 3}

While the authors have undertaken a literature review (200 titles), it is not necessarily exhaustive. It is likely that there are many more publications that could be reviewed with potential findings that could be incorporated into the southern Alberta EGS Assessment framework. The EGS Assessment is very important and complex, and additional work is required to fill in many of the existing gaps. 


\section{Discussion Point 4}

One of the objectives of the assessment is to "Provide an understanding of the value of high quality ecosystems in relation to economic production in southern Alberta,..."(pg 5). Figure 3-I of the report (pg 12) presents a conceptual framework of the function of ecosystem services. However, the figure does not carry a clear message, as it does not provide specific details or an explanation of the different types of arrows. No other framework of the value assessment of ecosystems is provided. Below is a figure that could be used as a starting point for the framework (from De Groot et al. (2002) in Barg and Swanson (2004) written for Agriculture and Agri-Food Canada). The clear division of ecological, socio-cultural and economic values could facilitate the value assessment of ecosystem services in southern Alberta. 


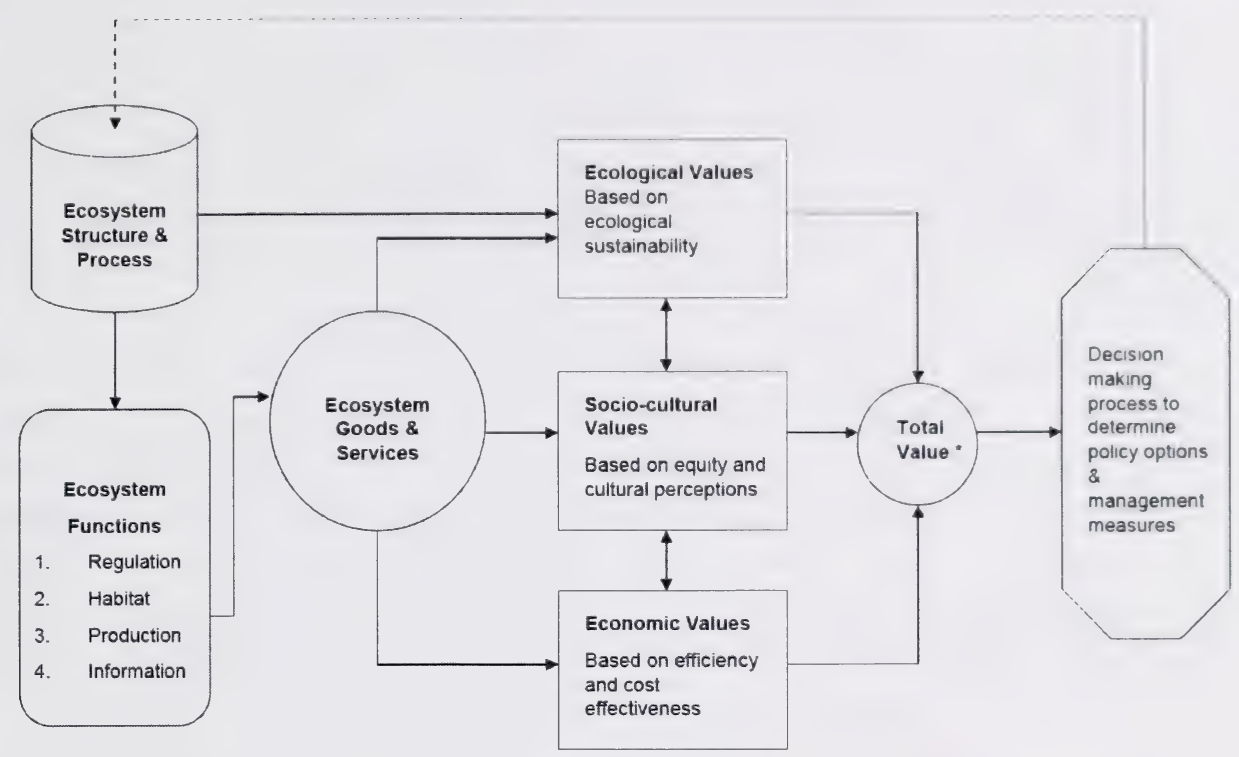

Figure I: A framework for integrated assessment and valuation of ecosystem functions, goods and services (from De Groot et al. (2002) in Barg and Swanson (2004) written for Agriculture and Agri-Food Canada)

\section{Discussion Point 5}

There is merit in distinguishing renewable and non-renewable goods from natural assets. Renewable goods have potential for long-term sustainable production. In contrast, non-renewable goods, such as fossil fuels, provide a limited service in terms of tonnes of coal or gas that can be extracted. Therefore, the management of assets providing a non-renewable good would be different from the management of an asset providing a renewable good.

A division could be made as follows (Brown et al. 2006):

- Nonrenewable

Rocks and minerals

ㅁossil fuels

- Renewable

- Wildlife and fish (food, furs, viewing) 
- Plants (food, fiber, fuel, medicinal herbs)

․ Water

$\square$ Air

Soil

․ Recreation, aesthetic (e.g., landscape beauty), and educational opportunities

\section{Discussion Point 6}

There is merit in dividing crop farming into irrigated and dryland farming. Southern Alberta has a high intensity irrigation industry, and irrigated agriculture is by far the largest water user in southern Alberta. As irrigated agriculture depends heavily on snow pack (which may decline under climate change conditions) and on an extensive reservoir-canal water delivery system, irrigated agriculture depends on natural and anthropogenic assets and ecosystem services that differ from those required by dryland farming. An additional benefit in singling out irrigated agriculture is there are increasing pressures due to potential future water shortages in southern Alberta. Furthermore, the value of irrigated agriculture will have to be compared with the value of all other water-demanding stakeholders.

\subsection{Review the relationships}

Question: Review the relationships (excel spreadsheets) between the goods, services and assets and flag areas of perceived discrepancy (provide reasoning).

\section{Discussion Point I}

The relationships are generally acceptable as tools to spurn discussion and to develop the next steps towards the ultimate aim of the EGS Assessment. It is clear that the relationships are based on professional opinion and we do not contest the opinion. Rather, we suggest that habitat (vegetation) based assets that include Native Prairie Assets and Forest Assets, all have a very similar relationship with the Services. We suggest that all of the cells in Appendix 9-3 for Provisioning Services (Native Prairie Assets and Forest Assets) could be filled in red (high importance). This is because all assets can be seen as equally capable of storing and retaining water; that is, they carry out this storing and retaining function with the amount of water that is available to them. In other words, the importance of storing water by fescue grassland is equal to the importance of storing water by mixedwood forest because the fescue grassland stores as much water as is available in that area. The concept is that removing the asset fescue grassland from an area would have disastrous consequences on the water retention potential (hence ecology) in that area. 
Moreover, we believe that the importance of the vegetation assets to food production, raw materials. and genetic resources is undervalued by being rated as low and should be rated as either medium or high importance (orange or red in current colour scheme). There are numerous aspects of western culture that can be listed here to rationalize the importance of, for example, genetic resources to medicines. We agree that the importance of these assets for traditional users is tremendous as indicated by the highlighting of traditional use under Cultural Services. However, within the spreadsheets, just mentioning that cultural services have positive relationships with aquatic assets is not as useful. This relationship needs to be analyzed and explained, preferably through examples. If we are able to demonstrate how a cultural service is well represented in the aquatic ecosystem then the reader or manager can use that understanding to define a personal approach in mitigating threats and opportunities in such aquatic ecosystems. Ranking in numbers or using a standard formula in assessing the importance of an asset in maintaining a service may be another option at viewing this relationship.

The following points are not exhaustive; they serve more as an example for further and on-going discussions and refinement:

\section{A. Excel Spreadsheet: Workbook: Relshp Services + Assets (Appendix 9-2)}

Water Supply and City/Town Relationship is a difficult one, as there are both positive and negative relationships: cities are typically net water producers, but storm water runoff is often contaminated. Therefore, the relationship should be classed as neutral to somewhat positive.

\section{B. Excel Spreadsheet: Workbook: Imp. To maintenance of assets (Appendix 9-3)}

Ice on Water Regulation and Water Supply should be red (high importance), as ice can withhold water for later melt, and also provide water under melting conditions. Studies are underway to investigate the importance of ice on late summer streamflows.

Roads/Trails on Water Regulation should be at least orange (medium importance), as roads in the prairie region of southern Alberta change natural watershed boundaries and may change the retention of water (Duke et al. 2003, 2006). This is because roads in the prairies are raised to prevent snow accumulation, thus typically acting as dams. Many ditches along roads act as artificial wetlands.

a City/Towns on Water Regulation should be red (high importance), as cities are typically net water producers due to the sealed surfaces of roofs, drive-ways, roads, parking lots etc., resulting in increased surface runoff into rivers, often with associated pollution problems due to the flushing of any substance that is on any of the sealed surfaces into the storm water drains. 
- Wellsites on Water Regulation and Water Supply should be red (high importance), as the concentrated use of groundwater can deplete the water table and render the well sites useless, as has happened in recent years in Bragg Creek, for example. About one quarter of all households in Alberta depend on groundwater.

Reservoirs on Water Regulation should be red (high importance), as the sole function of a reservoir is to regulate water.

\section{Excel Spreadsheet: Workbook: Imp. To production of goods (Appendix 9-4)}

- Water Supply on Health should be red (high importance), as water can carry contaminants. Regular health warnings are issued on river beaches every summer due to $E$. coli contamination, and then there was the Walkerton incident.

D. Excel Spreadsheet: Workbook: goods - water reg (Appendix 9-10)

- It is not clear why Forest Shrub, Hardwood Forest, or Mixedwood forest are classed as providing an important (red) water regulating service to Livestock, but not to Crops/Vegetables.

- Are not all Hydrographic Assets providing a water regulation service to crops/vegetables (if they are irrigated) and livestock?

Do the soils not provide the essential water regulation service as a growing medium for crops/vegetables?

E. Excel Spreadsheet: Workbook: goods - water sup (Appendix 9-19)

It is not clear why Forest Shrub, Hardwood Forest, and Mixedwood Forest are classed at providing an important water supply service to Livestock, but not to Crop/Vegetables.

Are not all Hydrographic Assets providing a water supply service to crops/vegetables (if they are irrigated) and livestock?

Are not most processes in the secondary sector relying on water supply?

Do the soils not provide the essential water supply service as a growing medium for crops/vegetables?

Why is the importance of wellsites on Trade classed as moderately important (orange)?

F. Excel Spreadsheet: Workbook: Imp. at the margin goods (Appendix 9-28)

- Water Supply on Wellsites must be red (high importance), as well sites are unusable if the water table declines (see note above). 
Water Supply on Feedlots must be red (high importance), as feedlots rely on the food produced in its vicinity. Recent drought years have shown the impact of the lack of feed (because of a lack of water) on feedlots.

G. Excel Spreadsheet: Workbook: Knowledge of the function (Appendix 9-31)

- Native Prairie Assets and Forest Assets on Water Supply (or vice versa) must all be at least orange (medium importance), if not red (high importance), as the principle functions of vegetation on water supply through the hydrological processes of interception, water demand, water extraction from the soil, and stress behaviour, are quite well understood.

Bare soil \& Rock on Water Supply (or vice versa) must be orange (medium importance), as slope stability along the coulees for example, or events such as Frank Slide, are consequences of the moisture situation.

Regardless of the ranking of importance that different users (and reviewers) may see, we would like to point out the similarity of relationships between all vegetation assets and the services listed here. As such, it may be useful to group or lump vegetation assets in one block of assets, which may be called "natural vegetation" (which can be defined in the EGS Assessment to not include Agricultural Assets). This way only one item would need to be considered in regional planning for the purpose of delivering the practical information to decision makers.

\subsection{Offer Additional Perspective}

Question: Offer additional perspective, opinion and recommendations related to topics they feel are of importance.

\section{Discussion Point I}

Compiling all vegetation assets into one would help decision makers streamline the question "What is the condition of natural vegetation?" by avoiding repeating the same question for each of the vegetation assets. Such an approach would allow for a sequence of scales to be explored, such as by asking about the condition of natural vegetation in the region, in a part of the region, in a valley, and on a farm. Conditions could then be more completely described by asking questions about specific vegetation assets at any of the scales. The condition of the individual assets would need to be known for detailed planning, but the question about natural vegetation overall, as a first step in directing management efforts would be a practical approach. 
For understanding vegetation assets and evaluating their conditions, the approach to measuring landscape parameters as described in Section 4.4.I of the EGS Assessment is sensible and would provide a useful planning tool, if interpreted by trained landscape ecologists. However, please note that Table 44: Potential Implications to Ecosystem Services resulting From a Change in Asset Condition is difficult to understand as the Table does not present any information on assets or their condition. How does the condition of assets relate to the services that are listed here? Which assets do the services refer to in this Table?

For future consideration, economic valuation is an appealing tool that offers a straight forward number which can be used in prioritizing the importance of ecological assets. However, in order to achieve the ultimate aim of prioritizing assets, a dollar figure may not be the best measure to use. Decision makers may not need to know how much money somebody is willing to pay for the rights to hunt an endangered animal or the costs of logging a sensitive habitat in order to set priorities. Rather, decision makers may be more receptive to the importance that people assign to any given asset. Appendices 928 to $9-31$ are indeed useful tools in understanding the importance overall. These tools can be used interactively with people, in order to consult with them on the importance of any given production of goods. Their inputs can then be linked to the assets and the assets' conditions that support these goods. As such, dollar figures become unimportant.

In terms of assigning importance to wildlife and habitat resources, the work has largely been done. This is because resource agencies have already developed a listing of species and habitats that require protection. The challenge in achieving the ultimate aim of the EGS Assessment is that the relationship between asset condition and asset value is usually non-linear. With multiple assets being evaluated by multiple stakeholders with multiple value systems, the tasks of balancing the maintenance of assets with the goods and services they provide is complex at best. Multivariate statistical approaches to the development of guidelines that incorporate the conditions and the importance of assets may help clarify the complex relationships among variables. Also, constraints mapping (identifying areas of cultural or environmental importance) may provide visual tools that help in the prioritization of asset protection in the region.

\section{Discussion Point 2}

The authors state that watersheds, the units for water supply, offer the only provisioning service that utilizes the top six important services. They also state that the water supply "was seen to be of high importance to fourteen asset types, the most of any service. Water supply was most important to anthropogenic assets rather than natural assets, including nearly all agricultural landscapes, rural/agricultural residential, cities and towns, industrial sites, reservoirs and canals." Therefore, it may be advantageous to use watersheds as the dominant spatial unit within which to carry out detailed EGS Assessments. This concept has been explained by Jewitt (200I), who states: 
"The catchment boundaries may influence local atmospheric transport and local climate, migration flows and the associated patterns of species distribution, as well as dispersion flows of pollution. The quantity and quality of water serves as an indicator of the relief and landscape characteristics, on the one hand, and as an integrator of many of the processes occurring within the catchment, on the other."

"Can Integrated Water Resources Management Sustain the Provision of Ecosystem Goods and Services? The use of the catchment as a management unit may also account for other factors, both of ecological and social origin. ... Consequently, much of the human population and the associated anthropogenic pollution, and other forms of environmental stress are often tied to the river network. The assumption that the catchment offers an optimal spatial scale for the management of ecosystems, may not necessarily be valid, however, it has become accepted that catchments offer a good compromise as a spatial unit on which to focus management strategies."

Based on the importance of water in southern Alberta, the current and growing recognition about the risks of water shortages, and the increasing problem of apportioning the water to stakeholders, many studies are based on watersheds of various sizes. In addition, the Beneficial Management Practices Initiative water quality studies are based on watersheds. It is, therefore, recommended to integrate watershed boundaries as an assessment unit. As the assessment and management is likely to be carried out within political boundaries, such as counties, an overlay of sub-watershed boundaries (watershed size could be between 100 and $2000 \mathrm{~km}^{2}$ ) where county boundaries could provide assessment units.

\section{Discussion Point 3}

It appears that real-life scenarios or examples are missing or lacking from the report. One of the objectives of the report is to determine the spatial pattern of the landscapes that should remain relatively undisturbed in Alberta in order to sustain the delivery of EGS. This point is not really emerging from the report. Ideally the current conditions of several or selected ecosystems in southern Alberta should be discussed that would allow mitigation measures to be suggested for sustaining the delivery of EGS.

\section{Discussion Point 4}

It is very important to understand why Southern Alberta needs an EGS Assessment. What is different in this EGS approach that is not addressed in other similar programs such as the Alberta Biodiversity Monitoring Program, Integrated Landscape Management, etc? If the new approach is justified, how does this EGS approach add value to the existing approaches? We believe that the EGS should compliment other programs (and vice-versa) and not duplicate, in whole or in part, other provincial programs.

\section{Discussion Point 5}

Valuation of the EGS is primarily important. Particularly, examining how the costs and benefits of an ecosystem are distributed is fundamental; different stakeholder groups often perceive very different 
costs and benefits from ecosystems. Understanding the magnitude and mix of net benefits received by particular groups is important for two reasons. From a practical perspective, groups that stand to 'lose' from conservation may seek to undermine it. Understanding which groups are motivated to conserve or destroy an ecosystem, and their reasons why, can help to design more effective conservation approaches. From an equity perspective, the impact of conservation on particular groups such as the indigenous peoples is often of significant concern, in and of itself.

\section{Discussion Point 6}

It has been acknowledged that there has been no involvement of the public in this initial assessment of ecosystem goods and services. Given that one of the major hurdles in the EGS Assessment process will be informing the public about what EGS are and why they are important, it is not clear why consultation activities have not been initiated. Careful consideration of how to consult the myriad public interest groups (conservation groups, farming co-operatives, land developers, Aboriginal groups and First Nations) is required. What is clear is that the EGS Assessment (as is) is not what should be presented to the public. The EGS Assessment process has moved forward, but has a long way to go before becoming one of several useful tools for policy developers and decision makers. However, the underlying meaning of EGS and its relative importance needs to be understood by both the public and those who are championing the process. The use of constraints mapping in a public forum to identify opportunities and restrictions may be of value in the public consultation process.

\subsection{Respond to the following key questions}

Question: Respond to the following key questions put forth by AENV and the consultants who completed the EGS assessment (Integrated Environments Ltd and 02 Planning + Design);

1) The approach used to determine the importance of, and relationships between, goods, services, and assets was based on professional opinion. This was done by consensus in a team of five professionals consisting of environmental landscape planning experts. Was this approach appropriate for this study? Are there alternate approaches that could have been used?

Ecosystems provide a wide variety of useful services that enhance human well-being. The Ecosystem Approach (EA) places human needs at the centre of biodiversity management. It aims to manage the ecosystem, based on the multiple functions that ecosystems perform and the multiple uses that are made of these functions. The ecosystem approach does not aim for short-term economic gains, but aims to optimize the use of an ecosystem without damaging it. With this background, any EGS Assessment would require a multi-disciplinary approach. The EGS Assessment and 
planning team must include ecosystem management experts, conservation economists and biologists, biodiversity planners, water resource experts, landscape and geography personnel. Overall, as a first approximation, the use of professional opinion is acceptable. However, the biases of environmental landscape planning experts may not adequately represent the multiple visions of resource use of the people that live in the southern Alberta region. We need an integrated ecosystem approach to science that gets the public involved in collecting data and in discussing the significance of findings before advice goes to the policy and decision makers. Ideally, any EGS Assessment should have wider participation of the diverse stakeholders and contributors at the planning stage because many sectors of society would benefit or be disadvantaged from the results of EGS. Ongoing and extensive review and expansion (systematic surveys) is required to evaluate the initial findings.

In addition, report authors could provide a synopsis, in the beginning of the report, of the various worldwide EGS approaches and then justify the approach selected as a priority choice for southern Alberta. This would be useful background information for resource managers to fully understand the rationale behind the selected EGS framework.

2) Was the scope of this study appropriate? (consider geographical area, the breadth of services, goods and assets considered, and any others)

For the landscape ecology portion, and the regional and conceptual scale at which this was done, the scope seems appropriate. Overall, it is a good starting point and provides a good planning tool for further design of on-ground EGS evaluations. We point out, however, that the authors are aware of the various needs for further study (see last bullet pg 2).

Most of the information with regard to the impact of the anthropogenic factors is very general or rather relative. Even if it was not possible to collect information for the whole southern Alberta area, it may be possible to conduct pilot assessments involving detailed analysis of anthropogenic impacts on a certain ecosystem type to show the relative linkages and aftermaths. For example, a figure could have text boxes indicating a specific ecosystem in the Rockies and EGS elaborated around it for clarity sake. Overall, an in-depth study of various parameters is required for any given area, preferably with good field data collected for the purpose of EGS Assessments. 
As well, decision makers need objective technical assistance to identify the opportunity and risks of using different types of market instruments for ecosystem services and for designing them to be effective, efficient and equitable (Kumar 2005).

Given the large area covered by the present EGS Assessment, and the myriad underlying interests found within such an expansive and geographically diverse region, consensus of approach in future EGS Assessment development may prove difficult to achieve.

3) Are the components of the framework (i.e. specific ecosystem services, goods, and assets) appropriate to this type of assessment in this region? Are there any that should be added or removed?

Wildlife assets and biodiversity are apparently poorly represented. It appears that they are intended to be under the umbrella of vegetation/habitat types which may be acceptable in many instances. However, wildlife indicator species and several provincially and federally listed species (of which there are many in the prairie ecosystems) may not be protected under the umbrella of a vegetation type. Similarly, rare plants may not be protected under the umbrella of vegetation type, instead requiring a more detailed level of plant classification. The inclusion of wildlife species as indicators of asset condition (as used in this report) will need to be developed. As well, the human linkages with the whole ecosystem appear to be poorly represented within the EGS Assessment.

One important good that should be added in the assessment is power generation. Both hydro and coal-based power generation depend on a constant water supply. During the recent 2001-2002 drought, a coal power plant needed to be shut down due to the lack of cooling water (Kienzle 2006). This situation is likely to be exacerbated with climate change due to possible longer and more severe droughts.

As discussed earlier (Section 2.3, Discussion Pont I), the various vegetation assets could be lumped under the umbrella of "natural vegetation" (vs. agricultural vegetation).

4) Is the level of detail shown in the conceptual diagram (page 32) sufficient to reveal the largescale relationships between goods, services, and assets in Southern Alberta? Is this diagram useful?

The diagram looks impressive at first glance because it shows conceptual linkages among assets, ecosystems services and goods. However, how does the knowledge of these 
linkages help in achieving the Ultimate Aim? The causal relationships are quite unclear. as no directions of linkages are provided, and potentially more classes (or percentages for better weighting) should be used. Even though the Figure would become very complex, linkages to each of the elements of Assets, Goods and Services (e.g. Cereal crops, erosion control) should be established. Arrows should be added to show single or bi-directional relationships and the links need to be cross-checked carefully. For example, the link between Agriculture and Regulating Services should be a strong link because farming practices have an impact on erosion and sediment transport.

5) The following relationships are modeled in Chapter 4:

- services that maintain assets,

- services that produce goods,

- importance of services at the margin,

- ability to manage an asset,

- impact of expanding anthropogenic assets on services, and

- impact of asset condition on goods and services.

Are these relationships sufficient to explain the role of EGS in southern Alberta? And, was the approach taken to modeling of these relationships useful? Are there any alternate approaches that you would suggest?

As discussed above, a major omission is that the relationships of assets on goods and services were not modelled. It would also be useful to consider how these relationships help advance towards the ultimate aim of the EGS Assessment.

6) The analysis of the spreadsheets in the report was based on assigning a qualitative value of high, moderate or low importance between the two variables under consideration as described above. Assess the validity of this approach and the results.

The presentation of the results is relatively easy to follow, but it is very simplistic. As any evaluation that is based on classification, the fewer classes, the more general the approach. Three classes are acceptable for a very first rough evaluation, but more classes should be used for a complete assessment in the future. It may be valuable to give examples of real-life ecosystem and or habitat types and relate their EGS importance accordingly. In that way, the relative importance of a Service or Good can be demonstrated.

The underlying issue is that relationships like these are multidimensional and occur at different scales. We do not argue that the approach is invalid; rather, we think that a 
great deal more work needs to be done to understand the multivariate nature and its operation at any of the scales to be examined. A first step would be to determine the scale at which the ultimate aim should be achieved, and then to review how recent research on multiple ecological scales might be used in developing guidelines.

Overall, the report seems theoretical from the user point of view. It may serve as a broad guideline, but most resource managers and policy makers would still need to begin by defining linkages for their own ecosystem problems and integrating the various critical parameters.

7) Section 4.5.I ranks the importance of ecosystem services to the production of goods. To complete this ranking the "basket of goods" that may be produced by each asset was determined. The importance of a given service to the production of each good was then averaged for all goods within an asset. This approach was taken to show the importance of services to goods within a summary table listing assets rather than goods. Is this approach easy for a reader to understand? Is there a better way to accomplish this analysis of importance of services to the production of goods?

In fact, we find this issue rather confusing. The reader does need to look into the details of Section 4.2 of the EGS Assessment in order to try to understand this approach. However, even in doing so, the use of goods versus assets and how that plays out in the analysis is not readily comprehensible. Moreover, the question of the validity of such ranking, as referred to below, is very important. It is unclear what could be achieved with this ranking, since each stakeholder, as well as each scientific discipline, would develop a different ranking.

We suggest that the intention of the ranking be clarified in terms of its goals, its relationship with the ultimate aim of the EGS Assessment and to the stakeholders or the disciplines that it expects to inform. It may also be useful to take examples from the rest of the world and make linkages to southern Alberta, so that a resource manager could visualize the importance of Services to Goods and Goods to Services.

8) Do the rankings of services with respect to the function of maintaining assets (section 4.5.2) make sense based on your understanding of ecosystem services in southern Alberta? And, there is concern that the lower ranked services may be seen as unimportant by some who read this report. However, these services can be fundamental to the integrity of ecosystems in Alberta (e.g. Habitat/Refugia). Does the text of this report make this point clear, and with enough emphasis? 
In the spreadsheet for the Summary Overall Ranking, it is interesting to see that Woter Supply is ranked similarly to Erosion Control and Sediment Retention, and lower than Nutrient Cycling. Erosion control and sediment retention are not major and wide-spread issues in southern Alberta and should be ranked lower than Water Supply. And Nutrient Cycling, while clearly essential, should not be ranked higher than Water Supply, which has a major impact on Nutrient Cycling. Appropriate ranking changes should be made.

Most resource managers and policy makers will understand the underlying concept that none of the assets are mutually-exclusive, stand-alone entities that have been labelled important in their own right. However, public consultation efforts will need to emphasize this underlying concept in a plain-language format.

We would also like to add that different stakeholders may well look at the rankings in rather different ways. This is particularly true for Traditional Resource Users who often maintain that "everything is important". Indigenous human populations have diverse uses and relationships with the ecosystems and their goods. In fact, there are multidimensional benefits or uses that are drawn from one asset. For example, in a mountain ecosystem, people may use a certain plant or a community of plants for protecting their backyards, making an enclosure for their livestock and burning as a fuel. However, the same plant community may be used by birds as a breeding habitat or nesting territory. while naturally serving the river in protecting its edges from widening (Sheikh et al. 2002). So there can be several users of the same asset that supplies a variety of services. Thus, how can you rank the different services without relating the rank to the user? Also, see comments under question 7.

9) The relative importance of ecosystem services is detailed in Appendix 9-7 to 9-26. This importance is based on four criteria: importance to the production of goods, importance to the maintenance of assets, importance at the margin, and the ability to manage an asset to provide the service. The knowledge of ecosystem service (column $G$ ) was described in the table, but not factored into the overall ranking). Are these criteria appropriate to determining the importance of ecosystem services in southern Alberta? Are there any you would add? Should these criteria be equally weighted? And, the ability to manage an asset to provide a service was positively factored into the overall rank for a service. That is, the higher our ability to manage an asset for a given service, the more important the service would be ranked. There may be some merit in a different approach, in that our ability to manage an asset to provide a service is irrelevant to the overall importance of a service. In other words, if a service is important to 
producing goods and/or maintaining assets - its importance is not impacted by our ability to manage assets. Is it a good idea to factor in our ability to manage a service? Why or why not?

The condition of an asset relates directly to its importance and thus, knowledge of its condition is fundamental to the evaluation of any given asset. We, therefore, believe that factoring in the ability to manage an asset (we understand the ability to manage as being a function of both the information we have about it and our physical ability of altering its condition) is of utmost importance. However, it may not be useful to throw management into the proverbial basket together with other factors. The ability to manage should be considered separately from the importance of an asset to any given goods or services. The ability to manage should be used in a secondary step of decision making.

Other factors to consider in the manageability of a service are:

- Identifying the specific sources of ecosystem services for proper valuation.

- Identifying and ultimately developing payment mechanisms, and identifying buyers and sellers of ecosystem services.

- Identifying the potential of the returns of EGS to enhance livelihoods, particularly for socially and economically disadvantaged groups.

10) What are the logical next steps in continuation of this work?

We believe that the following items are necessary for the continuation of the EGS Assessment:

- Conduct public and stakeholder consultations.

- Integrate an economic angle for a better understanding of the issues and opportunities.

- Extensive reviews of EGS approaches worldwide.

- Launch a pilot scale EGS evaluation exercise at a watershed level or for a major well-known ecosystem type in southern Alberta.

- Engage environmental ministries and agencies in promoting the role and value of ecosystem services in economic development, including within the context of international economic and biodiversity agreements. 
- Raise awareness within administrations of all sectors at the provincial level with respect to the role of ecosystem services in delivering their development objectives.

- Promote legislative frameworks and voluntary initiatives that enable markets for ecosystem services including those for carbon emission reduction and sequestration, watershed management, and biodiversity conservation.

- Promote true valuation of ecosystem services, including removal of subsidies and incentives.

- Complete a gap analysis of ecosystem coverage by protected areas to identify key opportunities for protected areas that can enhance local livelihoods.

- Enhance management effectiveness of protected areas to improve delivery of ecosystem services provided by those areas.

- Ensure congruence with Federal and Municipal Government land use policies and frameworks.

11) How do you see using this information in its current form being used to support environmental decision making, environmental management policy development and planning?

It may be difficult for managers and decision makers to use the information unless it is simplified. By understanding how ecosystem valuation is important, they can weigh the importance of EGS and act accordingly. It was noted by both peer-reviewers and EGS Assessment authors that until the information is refined and made spatial (mapped) the utility of the current information is limited (see comments below in response to Question 12).

It might be more effective to use language or words from within the resource management working systems rather than economical terms. Managers, researchers and policy makers are prone to use those institutional working words on a daily basis. This would help in saving time and simplifying the concepts.

12) If we could make this information spatial, what questions would you suggest the maps attempt to answer?

Spatial analysis is an essential component of the EGS Assessment. As indicated earlier in this review, identifying and integrating all possible linkages among assets and services will likely be an impossible task. However, the question of "How much information do we need to make an informed decision about asset X?" needs to be posed. An ecosystem 
can be defined as a geographically specified system of organisms (including humans), the environment, and the processes that control its dynamics. Any ecological good or service is spatially dependent on available ecological assets. In order to achieve the assessment of EGS, spatially dependent, multi-disciplinary, multi-scale and multi-temporal information needs to be integrated. Therefore, the use of existing and the establishment of new GIS databases with the development of spatial analyses procedures to qualify and quantify linkages between assets, goods and services is an approach that can add great value to an EGS Assessment. For example, the Millennium Ecosystem Assessment Project based the development of indicators on remote sensing, image processing, spatial data bases, and GIS technologies, coupled with modelling procedures (Heileman and MacDevette 2002).

Not only are the individual assets, goods and services spatially distributed, but they also have different spatial relationships. Cumulative impacts to assets, goods or services can be analyzed within a GIS framework. The evaluated importance of an asset, a good or a service can be mapped, and regions of higher relative importance can be distinguished from areas with lesser importance.

For example, irrigated agriculture is dependent on water supply, soils, climate, and the infrastructure to provide water and move and process the produced product. All these are spatially limited, as most of the water used by the plants is provided from the mountains, the soils need to have a certain quality to provide water and nutrients to the plants, and the climate varies spatially dramatically from southern Alberta's west to east, which, in turn, impacts the water demands. Further, the combination of soil and climate influences the optimum crops grown from these assets. The overlay and spatial analysis of all relevant layers can provide the water managers with information as to where the best crops can be grown with the least amount of water. Without spatial integration, this analysis is not possible. The integration of this approach with the current government/regulatory constraints surrounding irrigation districts would be required.

While it would be a massive task to establish all major links between natural assets and goods and services, both between individual GIS layers and spatially, it could provide the basis for a transparent and repeatable EGS Assessment. Further, the assets can be both quantified and qualified, thus allowing the impact analysis on the goods and services if one plans to change one asset (e.g. forest), or if one asset is undergoing a natural or unmanageable change on its own (e.g. climate change impact on snow pack and water supply). 
The authors state under point 2.3 (Limitations of the Assessment) that there was no intent to incorporate any spatial analysis. Due to time limitations by the authors, the actual spatial analysis was prohibitive. However, as spatial analyses can have a profound impact on the assessment itself, the concept of spatial analysis could have been integrated in the assessment.

While the authors list the assets based on Alberta Environment's spatial database, no spatial analysis or spatial representation was provided (other than the asset percent areas in Figure 4-1), and neither ecosystem goods or services were analyzed spatially or mapped. As the authors state correctly, the asset condition can only be assessed when patch size, connectivity and configuration are considered, which, again, can only be analyzed using a GIS. A number of spatial analyses requirements are listed under Section 4.4, such as Natural Asset Patch Size, Contagion of Natural Assets, Linear Disturbance Density, or Boundaries and Edges. However, no attempt is made to show how this influences asset condition.

The authors state under Gap \# 4 that more in-depth analysis of asset conditions is required. This statement should be extended much further, as ecosystem goods and services and their spatial linkage to ecosystem assets are essential for an EGS Assessment.

A list of potential maps (general scale I: 250,000 , but could vary) could include:

- Natural assets

- $\quad$ Current / future ecosystem services

- $\quad$ Current / future ecosystem goods

- For each of the goods/services listed throughout Section 4.3 of the EGS Assessment: distribution of goods/service, overlaid with natural and anthropogenic assets, e.g. livestock production, with linkages to natural assets (land base, food base, water courses, etc.) and anthropogenic assets (slaughter house, etc.)

- Relationships between assets and goods

- Relationships between assets and services

- Cumulative/combined assessment of ecosystem services

- Cumulative/combined assessment of ecosystem assets 
- $\quad$ Many more as the project evolves

As is, the EGS Assessment could be used to preliminarily identify 'hotspots' of concern rather than to examine general pattern analysis; the question of "Which areas are we concerned with now and where are they located?" could be answered, albeit the former half of the question almost intuitively. Areas providing a host of services could be identified. In turn, the EGS Assessment could then begin focusing or drilling-down further to make the identified areas of concern spatially explicit, with the premise of contributing to SAL and rank-and-file municipal land use planning decisions.

\subsection{Additional Discussion Highlights}

Below are some overarching comments on the EGS Assessment:

- The authors mentioned that EGS would contribute to the SAL; however, the report lacks the necessary connection here. Ideally a brief summary should be provided on SAL and then how the EGS Assessment will fill-in the gaps to increase the effectiveness of SAL.

- Protected Areas (PAs) are not discussed as they should be in this case. Southern Alberta has lots of leading PAs that needs to be given due consideration and assessment because most of the environmental services are obviously noticed within these areas. There are noticeable means and opportunities to investigate in protected areas because of effective control, liaison and organization of the protected environment and resources. EGS approaches could be well defined there and later replicated in other areas.

- Biodiversity is a wide and an interrelated term. It stands at the level of an asset and may also serve as a good due to the various services it performs by the ecosystems. It maintains the basis of the various assets. Forest, grasslands, prairies and aquatic systems are all key components of biodiversity. It may be recommended that biodiversity cannot just be regarded as a good coming out of the ecosystem processes.

- The authors briefly touch on the impact of expansion of anthropogenic assets on the ecosystem services. It is very general and may not be enough. It may be useful to conduct a quantitative analysis of the impact of certain anthropogenic factors and then measure the effectiveness of the services or assets (i.e., direct and indirect footprint of anthropogenic factors). This way it becomes more meaningful and practical to implement the plans. We probably need to avoid text book approaches and discuss examples from real-life scenarios. Imagine if an ecosystem planner has to evaluate what impact the growing housing development in Foothills Natural Region (FNR) has on the functioning of the ecosystems services or assets. How will he learn from the analysis provided in the report, as well as figure 4-I? The assessment should aim at providing guidelines and set of tools to achieve this purpose. 
- Consideration of EGS Assessment boundaries requires attention and careful planning. For example, consider the following:

- private, public and leased lands

- federal, provincial and municipal boundaries

- watershed boundaries

All of the above will require careful crossover planning by those attempting to use the EGS Assessment in any form.

\section{I Comments on EGS Assessment Gap Analysis}

We are of the opinion that the gaps identified as 5, 6 and 7 in the EGS Assessment (p. 88-89) should not be kept on low or medium priority, but rather should be made a high priority. For example, item 7. the coordination of the valuation of ecosystem goods and services with tools and instruments used in policy development to protect them, would probably serve as a strong basis of any practical EGS worldwide. At the time of valuation of ecosystems, an exchange of ideas should involve the policy and decision makers, who are ultimately going to be the users or managers of the information. If EGS Assessments are conducted in isolation from key stakeholders, they are less likely to be effective. Public consultation and sharing is as important as is the management and implementation of the EGS Assessment. The Ecosystem Approach places human needs and interests at the centre of biodiversity management. It aims to manage the ecosystem, based on the multiple functions that ecosystems perform and the multiple uses that are made of these functions. The ecosystem approach does not aim for short-term economic gains, but aims to optimize the use of an ecosystem without damaging it.

Understandably, the gap analysis is touching the most important points that were not integrated in the EGS Assessment approach to date. However, it is not clear why one or all of these points could not be integrated into the current assessment. Public consultation and involvement, as well as EGS design in line with policy development, are key essentials for an EGS approach to bring positive change and value to existing approaches.

\subsection{Management Challenges of the Current EGS}

How will an environmental manager or policy developer use the information from this EGS report (as it is) to improve his ecosystem management strategies? The intention is for a biodiversity planner or ecosystem resource manager to use this information to protect or sustain natural resources within his 
jurisdiction. To make the EGS information useful, the theoretical rankings and analyses should be transferred in the form of flow charts and practical examples should be given from the respective areas where the EGS recommendations are targeted. How would the information and guidelines in the current EGS assessment be used by a park ecosystem or biodiversity conservation planner to make conservation and sustainable use improvements? For example, in economic language it may be uncomplicated to say that ground level data on producer costs for managing ecosystem services, markets, and operational costs and the costs of establishing and operating different types of market instruments must be collected, synthesized and analyzed before providing anything useful on the functioning of markets for ecosystem services. If this is correct, what are the practical implications? How can any planner decide what is important for his or her park? Ideally, various prime habitats or ecosystems of southern Alberta should be listed first. EGS should then be applied to those ecosystems, modelling the various elements of existing natural and societal linkages.

\subsection{How Can this Program become more Meaningful?}

If an EGS was conducted using the valuation for various goods, services and assets and involving key stakeholders, then the implementation of results in various dimensions becomes much more meaningful. Ideally, EGS approaches should strengthen markets for ecosystem services, and identify new ones. These markets should allow companies to profitably invest, increasing value for their shareholders while enhancing contributions to community development and nature conservation. Experience shows that creating market incentives for ecosystem services is possible, but not simple. It may require sound science to document the volume, value and costs of providing ecosystem services, under alternative management regimes, as well as under vacillating political will and institutional commitment. Market incentives will establish payment and trading regimes for ecosystem services, whether on a voluntary basis, under local or national law, or as part of international agreements, and will aid institutional innovation to create viable business models and credible processes for monitoring, evaluation and public accountability. Recommendations include:

\section{Integrating Biodiversity Language into this report:}

Biodiversity can be interpreted as a form of natural insurance for risk averse ecosystem managers against the over or under-provision of ecosystem services, such as biomass production, control of water run-off, pollination, control of pests and diseases, nitrogen fixation, soil regeneration, etc. Thus, biodiversity has an insurance value, which is a value component in addition to the usual value arguments (such as direct or indirect use or non-use values, or existence values). In a world of uncertainty, this insurance value should be taken into account when deciding upon how much to invest into biodiversity protection. It leads to choosing a higher level of biodiversity than without taking the insurance value into account, with a higher degree of risk aversion leading to a higher optimal level of biodiversity (Baumgartner 2005). As far as the insurance function is concerned, biodiversity and financial insurance against income risk, such as crop yield insurance, may be seen as substitutes or equivalents. If financial insurance is available, a risk averse ecosystem manager, (e.g. a farmer), will partially or fully substitute 
biodiversity's insurance function by financial insurance, with the extent of substitution depending on the costs of financial insurance. Hence, the availability, and exact institutional design, of financial insurance influence the level of biodiversity protection.

Biodiversity science and protected areas systems are one of the most acceptable ways of understanding natural systems; however, it is felt that biodiversity science language, protected areas opportunities and their importance have not been fully realized in the EGS report.

\section{Increasing Investment in Ecosystem Services for People:}

Good landscape management will fulfill societal needs by equitably balancing trade-offs between the productive, social and environmental requirements of current land use. To function properly requires supportive policies, incentives and institutions that are capable of operating at the appropriate scale. It means conserving and restoring ecosystems so that they can fulfill their potential to support livelihoods. It means ensuring that the concerns of people depending on those ecosystems are taken into consideration when decisions are made. It also means incorporating the understanding of how a management action in one part of the landscape may impact another and allowing flexibility and adaptation in management responses for changing situations (Raju et al. 2007). Building on these three key challenges, and employing the key strategies of partnerships and knowledge mobilisation, a suite of more specific approaches is suggested as fundamental to success. A change in behaviour is needed. The political will for change is a necessary foundation for achieving success.

The concept of payments for ecosystem services is being developed as an important means of providing a more diverse flow of benefits to people living in and around habitats valuable for conservation. The Kyoto Protocol, under the United Nations Framework Convention on Climate Change, includes a Clean Development Mechanism to provide payments for certain forms of carbon sequestration that may benefit animal species (at least as an incidental benefit). Other market-based approaches for paying for carbon sequestration services outside the Kyoto framework are being promoted in various parts of the world. Another common form of payment for ecosystem services is compensating upstream landowners for managing their land in ways that maintain downstream water quality; this can include habitat management that benefits wildlife. While biodiversity itself is difficult to value, it can be linked to other markets, such as certification in the case of sustainably-produced forest products (McNeely, 2007).

\section{Explore and Support Payments for Ecosystem Services:}

The Millennium Ecosystem Assessment has provided a comprehensive overview of the ecosystem services upon which humans depend. Many of these services have been shown to have significant economic value in terms of their contributions to production and consumption (NRC 2004). Yet, most ecosystem services remain virtually free-of-charge at the point of use. Where supplies of ecosystem services are plentiful, relative to human demand, the lack of a price or some other mechanism to ration their use poses little problem. Increasingly, however, the growing demand for ecosystem services 
combined with external pressures on the ecosystems that provide them have led to scarcity, congestion, conflict and growing risks to human wellbeing. In this context, the continuing failure of markets to charge for the use of ecosystem services (or to reward the provision of ecosystem services) has become an increasingly severe constraint on long-term economic performance and sustainable development. While most ecosystem services are not traded in markets, there are important exceptions. 


\subsection{Recommendations}

For your consideration, the following recommendations, which are not necessarily mutually exclusive and are not in order of importance, are suggested to enhance the EGS Assessment framework:

- Consider that ecological systems include parameters that may or may not fit neatly into human economic systems. For example, "How do Prairie Wetlands maintain the service of water regulation?" While sometimes there are feedbacks from the services to the assets, this important point of critique has a large impact on the overall assessment. In addition to summing-up and reporting the services, the values of the assets (which, in part, should consider asset condition) should be summed-up also.

- Decision makers may not need to know how much money somebody is willing to pay for the rights to hunt an endangered animal or the costs of logging a sensitive habitat in order to set priorities. Rather, decision makers may be more receptive to the importance that people assign to any given asset. Appendices 9-28 to 9-31 are indeed useful tools in understanding the importance overall. These tools can be used interactively with people, in order to consult with them on the importance of any given production of goods. Their inputs can then be linked to the assets and the assets' conditions that support these goods. As such, dollar figures become unimportant.

- Organize workshops and conferences with very clearly defined objectives to bring together scientific experts, stakeholders, interest groups, stewardship activists, and conservationists. Prioritization of the list of assets would enable efforts to focus efforts on developing and implementing the EGS Assessment framework.

- Valuation of the EGS is primarily important. Understanding the magnitude and mix of net benefits received by various stakeholder groups is important for two reasons. From a practical perspective, groups that stand to 'lose' from conservation may seek to undermine it. Understanding which groups are motivated to conserve or destroy an ecosystem, and their reasons why, can help to design more effective conservation approaches. From an equity perspective, the impact of conservation on particular groups such as the indigenous peoples is often of significant concern, in and of itself.

- We need an integrated ecosystem approach to science that gets the public involved in collecting data and in discussing the significance of findings before advice goes to the policy and decision makers. Ideally, any EGS Assessment should have wider participation of the diverse stakeholders and contributors at the planning stage because many sectors of society would benefit or be disadvantaged from the results of EGS. Ongoing and extensive review and expansion (systematic surveys) is required to evaluate the initial findings. 
- The ability to manage an asset should be considered separately from the importance of an asset to any given goods or services. The ability to manage should be used in a secondary step of decision making.

- Consider the Phase 2 Report a dynamic document; continue the literature review on EGS Assessments and conduct an ongoing gap analysis.

- The relationships of assets on goods and services were not modelled. It would also be useful to consider how these relationships help advance towards the ultimate aim of the EGS Assessment.

- Implement more than an economical view point. For example, following the ideas by Costanza (2000), add community driven and holistic view points in the overall assessment.

- Decide on a sub-unit for the assessment. A combination of sub-watershed, municipal and county boundaries could be a good starting point. The benefit is that the assets, goods and services are likely to be both limited and unique in every unit, which makes the assessment much easier. It may be advantageous to use watersheds as the dominant spatial unit within which to carry out detailed EGS Assessments.

- Select several of the identified assets to be made spatial (mapped) and tested under the current or upcoming Land Use Planning Framework. It may be useful to consider a pilot scale EGS approach since that may highlight consequential results and strategies on ground. Data may also be collected and coordination may be more effective with all sectors of society.

- Conduct pilot assessments involving detailed analysis of anthropogenic impacts on a certain ecosystem type to show the relative linkages and aftermaths. For example, a figure could have text boxes indicating a specific ecosystem in the Rockies and EGS elaborated around it for clarity sake. Overall, an in-depth study of various parameters is required for any given area, preferably with good field data collected for the purpose of EGS Assessments.

- Additional factors to consider in the manageability of a service include:

- Identifying the specific sources of ecosystem services for proper valuation.

- Identifying and ultimately developing payment mechanisms, and identifying buyers and sellers of ecosystem services.

- Identifying the potential of the returns of EGS to enhance livelihoods, particularly for socially and economically disadvantaged groups.

- As multi-source, multi-format, multi-scale spatial data need to be integrated, establish a GIS database as the preferred data depository, enabling critical spatial analyses.

- Report authors could provide a synopsis, in the beginning of the report, of the various worldwide EGS approaches and then justify the approach selected as a priority choice for southern Alberta. 
This would be useful background information for resource managers to fully understand the EGS framework and the professional opinion behind the EGS approach selected.

- Integrate a Holistic (Nature-Society-Economy) approach.

- The inclusion of wildlife species as indicators of asset condition (as used in the EGA Assessment) will need to be developed.

- One important good that should be added in the assessment is power generation. Both hydro and coal-based power generation depend on a constant water supply.

- The causal relationships are not clear in Figure 3.2: Conceptual Lingages among Assets, Ecosystem Services and Goods (p. 32), as no directions of linkages are provided, and potentially more classes (or percentages for better weighting) should be used. Even though the Figure would become very complex, linkages to each of the elements of Assets, Goods and Services (e.g. Cereal crops, erosion control) should be established. Arrows should be added to show single or bi-directional relationships and the links need to be cross-checked carefully. For example, the link between Agriculture and Regulating Services should be a strong link because farming practices have an impact on erosion and sediment transport.

- The underlying meaning of EGS and its relative importance needs to be understood by both the public and those who are championing the process. The use of constraints mapping in a public forum to identify opportunities and restrictions may be of value in the public consultation process.

- Clearly define and document biophysical linkages between land uses and ecosystem service benefits, forest conservation and enhanced watershed services, terrestrial and aquatic biodiversity and corresponding benefits, carbon parking and related marketed benefits along with appropriate methods for measuring and monitoring the provision of services.

- The underlying issue is that relationships of assets on goods and services are multidimensional and occur at different scales. We do not argue that the approach is invalid; rather, we think that a great deal more work needs to be done to understand the multivariate nature and its operation at any of the scales to be examined. A first step would be to determine the scale at which the ultimate aim should be achieved, and then to review how recent research on multiple ecological scales might be used in developing guidelines.

- Other EGS approaches need to be reviewed and integrated firsthand from worldwide resources. A few readings and resources are suggested in the individual reports in the report appendix.

- Create information and maps practical for people who are going to implement the tasks. In essence, how will that information or maps be used by the resource managers? 
- Analysis for the site-specific design of market rules and institutions are still in the rudimentary stages and there exists a considerable gap in the knowledge base. In order to make it amenable for macro-analysis, careful synthesis of findings would be critically needed.

- Capacity building to develop national expertise in analyzing, designing and implementing ecosystem service markets in the public, private and civic sectors is needed at all levels and probably in every part of the world.

- There must be opportunities to exchange experiences, perspectives and lessons about the use and design of ecosystem service markets with peers in other countries and regions.

- Consider the EGS Assessment as being one of many tools/options to be used to identify areas requiring special attention during any development planning process.

- Consider the similarities and differences associated with ecosystem functions vs. ecosystem services (DeGroot et al, 2002).

- The gaps identified as 5, 6 and 7 in the EGS Assessment (p. 88-89) should not be kept on low or medium priority, but rather should be made a high priority. 


\subsection{Literature Cited}

Barg S. and Swanson D. 2004: Full Cost Accounting for Agriculture. International Institute for Sustainable Development, A paper written for Agriculture and Agri Food Canada (www.iisd.org/pdf/2006/measure_fca_2004.pdf)

Bator, F. M., 1958. Anatomy of Market Failure. Quarterly Journal of Economics 72:3 (August), 351-379.

Baumgartner, S., 2005. The Insurance Value of Biodiversity in the Provision of Ecosystem Services. Department of Economics, University of Heidelberg, Germany

Brown T.C., Bergstrom J,C, and Loomis J.B. 2006. Ecosystem Goods and Services: Definition, Valuation and Provision. RMRS-RWU-4851 Discussion Paper. http://www.fs.fed.us/rm/value/docs/ecosystem_goods_services.pdf

Costanza, R., d'Arge, R. et al. 1997. The value of the world's ecosystem services and natural capital. Nature 387:253-260.

Costanza R. 2000: Social goals and the valuation of ecosystem services. Ecosystems 3: 4-10.

Daily, G.C.,Sderqvist T., Aniyar S., Arrow K., Dasgupta P., Ehrlich P.R., Folke C., Jansson A., Jansson B., Kautsky N., Levin S., Lubchenco J., Muler K.G., Simpson D., Starrett D., Tilman D., and B. Walker. 2000. The value of nature and the nature of value. Science 289: 5478: 395-6.

Daily, G., 1997. Nature's Services: Societal Dependence on Natural Ecosystems. Washington, DC: Island Press.

De Groot R.S., Wilson M.A. and Boumans R.M.J. 2002. A typology for the classification, description and valuation of ecosystem functions, goods and services. Ecological Economics 41: 393-408.

Duke G., Kienzle S.W., Johnson D. and Byrne J. 2003. Improving overland flow routing by incorporating ancillary road data into Digital Elevation Models. Journal of Spatial Hydrology, Vol. 3, No. 2, (Fall 2003), 27pp.

Duke G., Kienzle S.W., Johnson D. and Byrne J. 2006. Incorporating ancillary data to refine anthropogenetically modified overland flow paths. Hydrological Processes, 20:1827-1843. 
Heileman S. and MacDevette D. 2002: Millennium Ecosystem Assessment Project - River Basin Assessments. Presentation for River Basin Information Systems Meeting, UNEP, Nairobi, I3-14 February 2002.

IUCN, The Nature Conservancy and The World Bank., 2004. How Much is an Ecosystem Worth? The World Bank, Washington DC.

Jewitt G. 200I. Can Integrated Water Resources Management sustain the provision of ecosystem goods and services? 2nd ARFSA/WaterNet Symposium: Integrated Water Resources Management: Theory, Practice, Cases; Cape Town, 30-31 October 2001.

Kienzle S.W. 2006. The Use of the Recession Index as an Indicator for Streamflow Recovery After a Multi-Year Drought. Water Resources Management. 20: 99I-1006.

Kumar, P. 2005. Market for Ecosystem Services. International Institute for Sustainable Development (IISD). International Institute for Sustainable Development 161 Portage Avenue East, 6th Floor Winnipeg, Manitoba. 32 pp.

McNeely, J.A., 2007. A zoological perspective on payments for ecosystem services. Integrative Zoology 2:68-78.

Millennium Ecosystem Assessment, 2003. Ecosystems and Human well-being. Island Press: Washington DC.

National Research Council. 2004. Valuing Ecosystem Services: Toward Better Environmental DecisionMaking. Washington DC: National Academy of Sciences.

Raju K.V., S. Puttaswamaiah and Rumley R., 2007. Asia Regional Workshop on Compensation for Ecosystem Services. A Component of the Global Scoping Study on Compensation of Ecosystem Services ICRAF Working Paper no. 34. Nairobi: World Agroforestry Centre.

Sheikh, K.M., Ahmad, T., and Khan M. A., 2002. Use, Exploitation and Prospects for conservation: People and Plant Biodiversity of NW Karakorums, Pakistan. Biodiversity \& Conservation.

Vorhies, F. 2003. Environmental Economics Explained. IUCN-The World Conservation Union, Gland Switzerland.

\section{Web Resources:}


www.iucn.org/ecosystems

http://www.biodiversityeconomics.org

www.biodiv.org

www.idrc.ca

http://www.wri.org/biodiv/pubs_description.cfm?pid $=3813$

http://www.iisd.org/ 
Appendix A: Individual Review Reports 


\section{EGS Review - Wildlife and Landscape Ecology Submitted by Dr. Petr Komers}

\section{Introduction}

We base our review on the stated goal of the Ecosystem Services Project, namely that the "ultimate aim is ... to deliver the right information to policy developers and decision makers..." Hereafter, we refer to this goal as the Ultimate Aim.

\section{Review Questions}

Evaluate the overall framework developed to highlight the relationships between the goods, services and assets and rank the importance of ecosystem services in southern Alberta.

The EGS Assessment presents a useful framework for assessing goods and services that are provided by landscape parameters which are composed of a mosaic of habitats and a diversity of wildlife that uses them. However, for discussion we would like to highlight the very anchoring question in this work: "How do ecosystem services support the maintenance of natural and anthropogenic assets?" Isn't this question backwards? Doesn't the asset support the service rather than the other way around? Would changing the thinking of how the services flow (i.e from assets to service to humans, rather than from service to asset to humans) make any difference to the development of a planning tool?

In this line of thinking, one would evaluate the condition of the asset which then would translate into the quality of the service that the asset delivers. One can easily see that a fragmented forest would provide less, for example, gas regulation or water retention, than an intact large tract of forest. We agree with the point raised by the authors that "there is a direct, although not always linear, relationship between the condition of natural assets and the type, quantity and quality of services they provide" (p. 60). This is an important recognition for decision makers, namely that the degradation of a service can increase exponentially with the degradation of an asset.

Of course, knowledge of asset condition is paramount to the Ultimate Aim. Although section 4.4 provides a useful generalized approach to evaluating asset condition, a great deal of work needs to be done before the Ultimate Aim will be reached. This work would involve the landscape scale measurement of composition, connectivity, and configuration, but it would also involve the evaluation of the asset components themselves, such as vegetation composition and wildlife population viability.

In general terms, we assume that condition affects importance. From an ecological management point of view, the importance of an asset increases with declining condition. For example, species (or habitats) that are rare are deemed important by resource managers. The highest importance is given to the most endangered species and habitats. As well, the amount of effort (in terms of time and money) that people are willing to invest into either experiencing or protecting an endangered species increases with the degree of endangerment. 
It follows that the value of an asset is determined by both the asset condition and the importance that people assign to the asset (there are many more aspects of how people may assign a value to wildlife assets which should be discussed elsewhere, but the point of importance the relationship between importance and value is made here in general terms). This leads to the question of economic value which was used as the anchor for this entire work (line 3 on page 3). We discuss below an alternative perspective on the framework of economic valuation as a tool for achieving the Ultimate Aim.

Review the relationships (excel spreadsheets) between the goods, services and assets and flag areas of perceived discrepancy (provide reasoning).

The relationships are generally acceptable as a tool to spurn discussion and to develop the next steps towards the ultimate goal. It is clear that the relationships are based on professional opinion and we do contest the opinion. Rather, we suggest that habitat (vegetation) based assets that include Native Prairie Assets and Forest Assets, all have a very similar relationship with the Services. We suggest that the cells in Appendix 9-3 for Provisioning Services could be filled in red (high importance). This is because all assets can be seen as equally capable of storing and retaining water, that is, they do that with the amount of water that is available to them. In other words, the importance of storing water by fescue grassland is equal to the importance of storing water by mixedwood forest because the fescue grassland stores as much water as is available in that area. One can think that removing the asset fescue grassland from an area would have disastrous consequences on the water retention potential (hence ecology) in that area.

Moreover, we believe that the importance of the vegetation assets to food production, raw materials, and genetic resources is undervalued by being rated as low. There are numerous aspects of western culture that can be listed here to rationalize the importance of, for example, genetic resource to medicines. We agree, however, that the importance of these assets for traditional users is tremendous as this point of traditional use is highlighted under Cultural Services.

Regardless of the ranking of importance that different users (and reviewers) may see, we would like to point out the similarity of relationships between all vegetation assets and the Services listed here. As such, it may be useful to lump vegetation assets in one block of assets, which maybe called "natural vegetation". This way, only one item would need to be considered in regional planning for the purpose of delivering the practical information to decision makers. 
- Offer additional perspective, opinion and recommendations related to topics they feel are of importance.

The above suggested compiling of vegetation assets into one would help decision makers to ask the question "What is the condition of natural vegetation?" without having to ask the same question for each of the vegetation assets. Such an approach would allow for a sequence of scales to be followed by first asking about natural vegetation in the region, then in a part of the region, in a valley, or on a farm. This could then be further specified by asking questions about specific vegetation assets at any of the scales. The condition of the individual assets would need to be known for detailed planning, but the question about natural vegetation overall as a first step in directing management efforts would be a practical approach.

For the understanding of vegetation assets and for the evaluation of their condition, the approach to measuring landscape parameters as described in 4.4.1 is sensible and would provide a useful planning tool, if interpreted by trained landscape ecologists. However, please note that table 4-4 is difficult to understand as the table does not present any information on assets or their condition. How does the condition of assets relate to the services that are listed here? Which assets do the services refer to in this table?

For future consideration, economic valuation is an appealing tool that offers a straight forward number which can be used in prioritizing the importance of ecological assets. However, in order to achieve the Ultimate Aim, a dollar figure may not be the best tool to use. Consider that decision makers may not need to know how much money somebody is willing to pay for the rights to hunt an endangered animal or the logging of a sensitive habitat. Rather, decision makers may be more receptive to the importance that people assign to any given asset. Appendices 9-28 to 9-31 are indeed useful tools in the understanding of the importance overall. These tools can be taken to people in order to ask them how important any given production of goods is to them which can then be linked to the assets and their condition that support these goods. As such, dollar figures become unimportant.

In terms of assigning importance to wildlife and habitat resources, the work has largely been done. This is because resource agencies have already developed a listing of species and habitats that require any given amount of protection. The challenge in achieving the Ultimate Aim is that the relationship between asset condition and asset value is usually non-linear. With multiple assets being valuated by multiple stakeholders with multiple value systems, the tasks of balancing the maintenance of assets with the goods and services that they provide is complex at best. Multivariate statistical approaches to the development of guidelines that incorporate the conditions and the importance of assets may be the 
required tools. Also, constraints mapping may provide visual tools in the prioritization of protecting assets in the region.

Respond to the following key questions put forth by AENV and the consultants who completed the EGS assessment (Integrated Environments Ltd and O2 Planning + Design); Question I: The approach used to determine the importance of, and relationships between, goods, services, and assets was based on professional opinion. This was done by consensus in a team of five professionals consisting of environmental landscape planning experts. Was this approach appropriate for this study? Are there alternate approaches that could have been used?

As a first approximation, the use of professional opinion is acceptable. However, consider that environmental landscape planning experts have a clear bias towards their biological training. The bias may not adequately represent the vision of resource use by people that live in the southern Alberta region. Systematic surveys may eventually be required.

Q Question 2: Was the scope of this study appropriate? (consider geographical area, the breadth of services, goods and assets considered, and any others)

For the landscape ecology portion, and the regional and conceptual scale at which this was done the scope seems appropriate. We point out however, that the authors are aware of the various needs for further study (last bullet page 2).

Question 3: Are the components of the framework (i.e. specific ecosystem services, goods, and assets) appropriate to this type of assessment in this region? Are there any that should be added or removed?

Wildlife assets and biodiversity are poorly represented. It appears that they are intended to be under the umbrella of vegetation which may be acceptable in many instances. However, wildlife indicator species and several listed species (of which there are many in the prairie ecosystems) may not be protected under the umbrella of a vegetation type. The inclusion of wildlife species as indicators of asset condition (as used in this report) will need to be developed.

Question 4: Is the level of detail shown in the conceptual diagram (page 32) sufficient to reveal the large-scale relationships between goods, services, and assets in Southern Alberta? Is this diagram useful?

The diagram looks impressive at first glance. However, upon further reflection question emerges as to how does the knowledge of these linkages help in achieving the Ultimate Aim? The causal relationships 
are quite unclear, particularly from a wildlife ecology point of view. The usefulness of the diagram is therefore questionable, but we concede that it does not hurt to have the diagram there.

- Question 5: Are these relationships sufficient to explain the role of EGS in southern Alberta? And, was the approach taken to modeling of these relationships useful? Are there any alternate approaches that you would suggest?

As a general conceptual start, thinking about these relationships helps to advance cowards the Ultimate Aim. As to alternatives, please see comments above.

- Question 6: The analysis of the spreadsheets in the report was based on assigning a qualitative value of high, moderate or low importance between the two variables under consideration as described above. Assess the validity of this approach and the results.

The presentation of the results is relatively easy to follow, but it is very simplistic. The troublesome fact is that relationships like these are multidimensional and occur at different scales. We do not argue that the approach is invalid, rather, we think that a great deal more work needs to be done to understand the multivariate nature and its operation at any of the scales. A first towards such work would be to determine the scale at which the Ultimate Aim should be achieved, and then to review how recent research on multiple ecological scales might be used in developing guidelines.

- Question 7: Section 4.5.1 ranks the importance of ecosystem services to the production of goods. To complete this ranking the "basket of goods" that may be produced by each asset was determined. The importance of a given service to the production of each good was then averaged for all goods within an asset. This approach was taken to show the importance of services to goods within a summary table listing assets rather than goods. Is this approach easy for a reader to understand? Is there a better way to accomplish this analysis of importance of services to the production of goods?

In fact we find this issue rather confusing. The reader does need to get into the details of section 4.2 in order to understand this. However, even in doing so, the use of goods versus assets and how that plays out in the analysis is not readily comprehensible. Moreover, the question on the validity of such rank as referred below is very important. It is unclear what should be achieved with this ranking. Each stakeholder, as well as each scientific discipline would develop a different ranking. 
We do not offer any new solution at this point in time, but we do suggest that the intention of the ranking be clarified in terms of its goals, its relationship with the Ultimate Aim and in respect to who the stakeholders or the disciplines are that it intends to inform.

Question 8: Do the rankings of services with respect to the function of maintaining assets (section 4.5.2) make sense based on your understanding of ecosystem services in southern Alberta? And, there is concern that the lower ranked services may be seen as unimportant by some who read this report. However, these services can be fundamental to the integrity of ecosystems in Alberta (e.g. Habitat/Refugia). Does the text of this report make this point clear, and with enough emphasis?

Please see the discussion under question 7. We should like to add that different stakeholders may well look at the ranking in a rather different way. This is particularly true for Traditional Resource Users who often maintain that "everything is important". How the can you rank the different services?

Q Question 9: The relative importance of ecosystem services is detailed in Appendix 9-7 to 9-26. This importance is based on four criteria: importance to the production of goods, importance to the maintenance of assets, importance at the margin, and the ability to manage an asset to provide the service. The knowledge of ecosystem service (column G) was described in the table, but not factored into the overall ranking). Are these criteria appropriate to determining the importance of ecosystem services in southern Alberta? Are there any you would add? Should these criteria be equally weighted? And, the ability to manage an asset to provide a service was positively factored into the overall rank for a service. That is, the higher our ability to manage an asset for a given service, the more important the service would be ranked. There may be some merit in a different approach, in that our ability to manage an asset to provide a service is irrelevant to the overall importance of a service. In other words, if a service is important to producing goods and/or maintaining assets - its importance is not impacted by our ability to manage assets. Is it a good idea to factor in our ability to manage a service? Why or why not?

The knowledge about the condition of an asset, which relates back to the importance of the asset, is fundamental to the evaluation of how valuable any given asset is. We therefore believe that factoring in the ability to manage an asset (we understand the ability to manage as being a function of both the information we have about it and our physical ability of altering its condition) is of utmost importance. However, it may not necessarily be useful to throw this item into the basket together with other factors. The ability to manage should be a consideration that is separate from the consideration of how 
important an asset is to any given goods or services. The ability to manage should be used in a secondary step of decision making.

Question 10: What are the logical next steps in continuation of this work?

Please see comments above.

Q Question 11: How do you see using this information in its current form being used to support environmental decision making, environmental management policy development and planning?

Please see comments above.

Question 12: If we could make this information spatial, what questions would you suggest the maps attempt to answer?

Please see comments above. 


\section{EGS Review - Water Resources \& Landscape Analysis Submitted by Dr. Stefan Kienzle}

I used the ABENV questions as the layout for this report. The review is not complete, as one could spend hundreds of hours reviewing concepts and details.

\section{Review questions:}

Evaluate the overall framework developed to highlight the relationships between the goods, services and assets and rank the importance of ecosystem services in southern Alberta.

While many points of the conceptual framework appear to be sound, I have to make the following general comments about the assessment approach:

\section{Monetary value of natural assets:}

I have a problem with the statement quoted by the authors (Page I): "The importance of the world's ecosystem services is substantial. Costanza et al. (1997) estimated their value at US\$33 trillion per year, about I.8 times current global gross national product (GNP)." Costanza et al. (I997) state further in their publication: "The services of ecological systems and the natural capital stocks that produce them are critical to the functioning of the Earth's life-support system. They contribute to human welfare, both directly and indirectly, and therefore represent part of the total economic value of the planet."

If one relates this number to the global population (assuming 6 billion), then everything supporting our lives (air, water, soil, plants, landscapes, food, materials, etc.) is valued at US\$ 5,500 per person per annum. Is this considered to be the value of a human being? If one were to take away any one of the services provided by natural assets, either water or air or soil or plants, then no life could survive.

It appears that there are some major under-valuations by several orders of magnitude in the value of the world's ecosystem services. This shows how inadequate many current economists' approaches are to put dollar values to natural assets. Civilizations died out (example: Sumerians in Mesopotamia) because one single element of the ecosystem (here: the soil) was degraded (here: salinization) to such an extent that food production was severely decimated. In the given example: What was the value of the soil? Is the value of the soil in this example not close to infinite? This is in line with Costanza et al. (1997), who state that in one sense the total value of ecosystem services to the economy is infinite.

In addition to the problem of evaluating a service provided by natural assets, there is a value that is extremely difficult to express in monetary terms, and that is the human perception of its surroundings for well-being. For example, what would the quality of our lives be without rivers and lakes? Or with 
only polluted rivers and lakes? There are services that the natural assets, as a whole, provide that we need for our spiritual survival.

Costanza (2000) suggests three types of value systems that are relevant to the problem of evaluating ecosystems services, which are efficiency-based values (self interest, economical view point), fairnessbased value (community view point), and sustainability based value (science based holistic ecological view point). Each view point has different requirements in terms of required discussion levels, the level of scientific input and scientific methods. The sustainability value basis is based, according to Costanza (2000) on scientific modelling with precaution. For the evaluation of water resources impacts under a variety of conditions, for example land use change, or climate change, or projected economical growth scenarios, complex and physically based hydrological model are available.

\section{An exhaustive Literature Review is required}

While the authors have undertaken a literature review, it may not necessarily be exhaustive. I have not had the chance to see the 200 titles of the annotated Bibliography, but I am convinced that there are many more publications that should be reviewed and where potential findings should be incorporated into the southern Alberta EG\&S framework. The EG\&S assessment is very important and complex, and additional work is required to fill in many existing gaps.

\section{Assessment framework}

One of the objectives of the assessment is (Page 5): "Provide an understanding of the value of high quality ecosystems in relation to economic production in southern Alberta,..."

Figure 3-I of the report presents a conceptual framework of the function of ecosystem services. This Figure does not carry a clear message, as it does not provide specific details and provides no explanation to explain the different types of arrows.

No other framework of the value assessment of ecosystems in provided. The figure below shows one such framework that could have been used as a starting point. The clear division of ecological, sociocultural and economic values could facilitate the value assessment. 


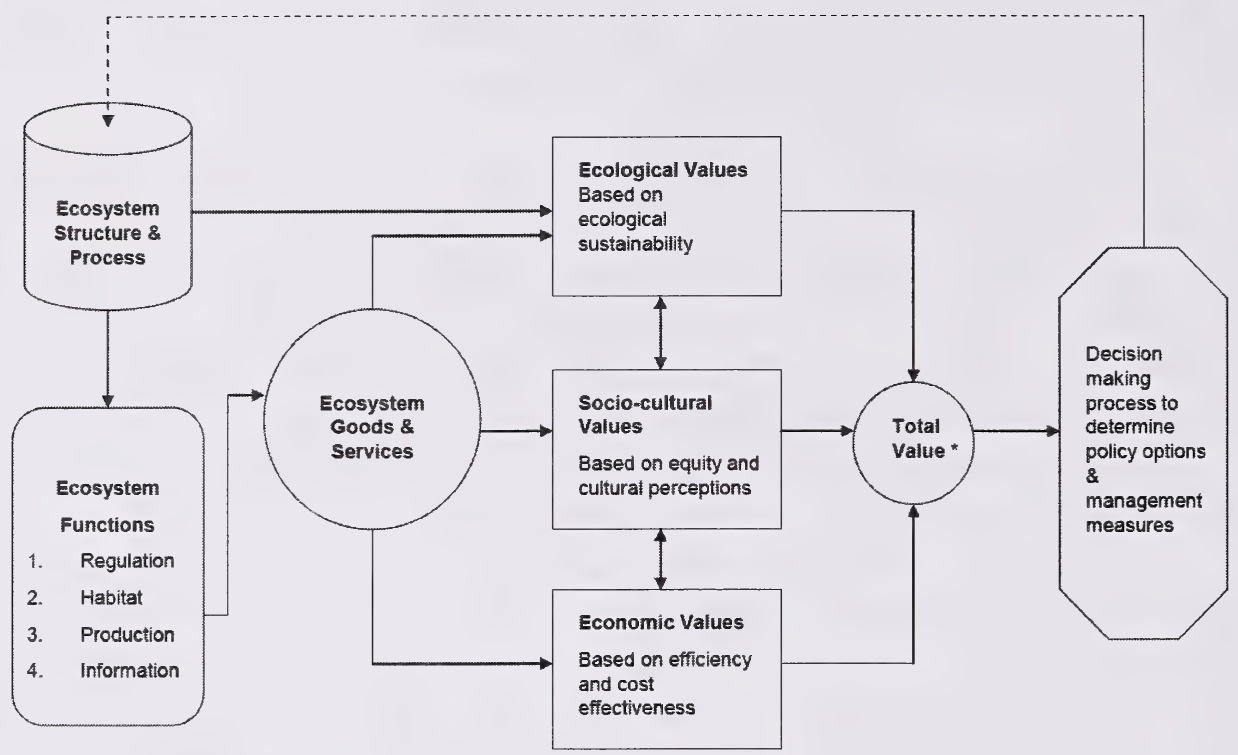

Figure 1: A framework for integrated assessment and valuation of ecosystem functions, goods and services (from De Groot et al. (2002) in Barg and Swanson (2004) written for Agriculture and Agri Food Canada

\section{Division of goods into renewable and non-renewable}

There is merit in dividing goods provided by natural assets into renewable and non-renewable goods, because non-renewable goods, such as fossil fuels, provide a limited service in terms of tonnes of coal or gas that can be extracted. Therefore, the management of assets providing a non-renewable good would be different from the management of an asset providing a renewable good.

A division could be done as follows (Brown et al. 2006):

Nonrenewable

- Rocks and minerals

- Fossil fuels

Renewable

- Wildlife and fish (food, furs, viewing)

- Plants (food, fiber, fuel, medicinal herbs)

- Water

- Air 
- Soil

- Recreation, aesthetic (e.g., landscape beauty), and educational opportunities

\section{Division of agriculture into irrigated and dryland}

There is merit in dividing crop farming into irrigated and dryland farming. Southern Alberta has a high intensity irrigation industry, and irrigated agriculture is by far the largest water user in southern Alberta. As irrigated agriculture depends heavily on snow pack (which is likely to decline under climate change conditions) and on an extensive reservoir-canal water delivery system, irrigated agriculture depends on natural and anthropogenic assets and ecosystem services that differ from those required by dryland farming.

An additional benefit in singling out irrigated agriculture is there are increasing pressures due to potential future water shortages in southern Alberta, and the value of irrigated agriculture will have to be compared with all other water-demanding stakeholders.

- Review the relationships (excel spreadsheets) between the goods, services and assets and flag areas of perceived discrepancy (provide reasoning).

The following points are not exhaustive; they more serve as an example for further and on-going discussions and refinement. Thus the following review is based on the relationship of the assets on the goods and services functions for Tables I, 7.

\section{Excel Spreadsheet: Workbook: Imp. To maintenance of assets}

Ice on Water Regulation and Water Supply should be red, as ice can withhold water for later melt, and also provide water under melting conditions. Studies are underway to investigate the importance of ice on late summer streamflows.

Roads/Trails on Water Regulation should be at least orange, as roads in the prairie region of southern Alberta change natural watershed boundaries and may change the retention of water (Duke et al. 2003, 2006). This is because roads in the prairies are raised to prevent snow accumulation, thus typically acting as dams. Many ditches along roads act as artificial wetlands.

City/Towns on Water Regulation and Water Supply should be red, as cities are typically net water producers due to the sealed surfaces of roofs, drive ways, roads, parking lots etc., resulting in increased surface runoff into rivers, often with associated pollution problems due to the flushing of any substance that is on any of the sealed surfaces into the storm water drains.

Wellsites on Water Regulation and Water Supply should be red, as the concentrated use of groundwater can deplete the water table and render the well sites useless, as has happened in recent 
years in Bragg Creek, for example. About one quarter of all households in Alberta depend on groundwater.

Reservoirs on Water Regulation should be red, as the sole function of a reservoir is to regulate water.

\section{Excel Spreadsheet: Workbook: Imp. To production of goods}

Water Supply on Health should be red, as water can carry contaminants. Regular health warnings are issued on river beaches every summer due to $E$. coli contamination, and then there was the Walkerton incident.

\section{Excel Spreadsheet: Workbook: Imp. at the margin goods}

Water Supply on Wellsites must be red, as well sites are unusable if the water table declines (see note above).

Water Supply on Feedlots must be red, as feedlots rely on the food produced in its vicinity. Recent drought years have shown the impact of the lack of water on feedlots.

\section{Excel Spreadsheet: Workbook: Knowledge of the function}

Native Prairie Assets and Forest Assets on Water Supply (or vice versa) must all be at least orange, if not red, as the principle functions of vegetation on water supply through the hydrological processes of interception, water demand, water extraction from the soil, and stress behaviour, are quite well understood.

Bare soil \& Rock on Water Supply (or vice versa) must be orange, as slope stability along the coulees for example, or events such as Frank Slide, are consequences of the moisture situation.

\section{Excel Spreadsheet: Workbook: goods - water reg}

- It is not clear why Forest Shrub, Hardwood Forest, or Mixed wood forest are classed at providing an important water regulating service to Livestock, but not to Crop/Vegetables.

- Are not all Hydrographic Assets providing a water regulation service to crops/vegetables (if they are irrigated) and livestock?

- Do the soils not provide the essential water regulation service as a growing medium for crops/vegetables?

\section{Excel Spreadsheet: Workbook: goods - water sup}

- It is not clear why Forest Shrub, Hardwood Forest, or Mixed wood forest are classed at providing an important water supply service to Livestock, but not to Crop/Vegetables.

- Are not all Hydrographic Assets providing a water supply service to crops/vegetables (if they are irrigated) and livestock? 
- Are not most processes in the secondary sector relying on water supply?

- Do the soils not provide the essential water supply service as a growing medium for crops/vegetables?

- Why is the importance of wellsites on Trade classed as Moderately Important?

\section{Excel Spreadsheet: Workbook: RelshpServices + Assets}

Water Supply and City/Town Relationship is a difficult one, as there are both positive and negative relationships: cities are typically net water producers, but storm water runoff is often contaminated. Therefore, the relationship should be classed as neutral to somewhat positive.

- Offer additional perspective, opinion and recommendations related to topics they feel are of importance.

\section{Direction of dependencies}

Daily et al. (2000) states: "The world's ecosystems are capital assets. If properly managed, they yield a flow of vital services, including the production of goods...".

The first research question stated by the authors (Page I) is: "How do ecosystem services support the maintenance of natural and anthropogenic assets?" The question appears to be reversed, as the question should rather read: How do ecosystem assets support the natural services and the anthropogenic goods and services? This has a major impact on the direction of dependencies. The way all spreadsheet tables are set up, they suggest that a service maintains an asset. Using a cow and produced milk as an example, the milk is the result of the condition of the cow: no cow - no milk, poor cow - little milk, good cow plenty of milk. The authors of the report ask (translated): how does the milk support the maintenance of the cow? Therefore, all spreadsheet tables must be read from assets to services, e.g. "How do Prairie Wetlands maintain the service of water regulation? While sometimes there are feedbacks from the services to the assets, this important point of critique has a large impact on the overall assessment. In addition to summing up and reporting the services, the values of the assets should be summed up also.

\section{More focus on watersheds}

The authors state that watersheds, the units for water supply, provide the only provisioning service utilizing the top six important services. It is also stated that water supply "was seen to be of high importance to fourteen asset types, the most of any service. Water supply was most important to anthropogenic assets rather than natural assets, including nearly all agricultural landscapes, rurallagricultural residential, cities and towns, industrial sites, reservoirs and canals." Therefore, it may be advantageous to use watersheds as 
the dominant spatial unit within which to carry out detailed EG\&S assessments. This concept has been explained by Jewitt (200I), who states:

"The catchment boundaries may influence local atmospheric transport and local climate, migration flows and the associated patterns of species distribution, as well as dispersion flows of pollution. The quantity and quality of water serves as an indicator of the relief and landscape characteristics, on the one hand, and as an integrator of many of the processes occurring within the catchment, on the other."

"Can Integrated Water Resources Management Sustain the Provision of Ecosystem Goods and Services? The use of the catchment as a management unit may also account for other factors, both of ecological and social origin. ... Consequently, much of the human population and the associated anthropogenic pollution, and other forms of environmental stress are often tied to the river network. The assumption that the catchment offers an optimal spatial scale for the management of ecosystems, may not necessarily be valid, however, it has become accepted that catchments offer a good compromise as a spatial unit on which to focus management strategies."

Based on the importance of water in southern Alberta, and the current and growing recognition about the risks of water shortages and the increasing problem of apportioning the water to stakeholders, many studies are based on watersheds of various sizes. In addition, water quality studies as part of the Beneficial Management Practices initiative are also based on watersheds. It is, therefore, recommended to integrate watershed boundaries as an assessment unit. As the assessment and management is likely to be carried within political boundaries, such as counties, an overlay of sub-watershed boundaries (watershed size could be between 100 and $2000 \mathrm{~km}^{2}$ ) with county boundaries could serve as assessment units.

- Question 1: The approach used to determine the importance of, and relationships between, goods, services, and assets was based on professional opinion. This was done by consensus in a team of five professionals consisting of environmental landscape planning experts. Was this approach appropriate for this study? Are there alternate approaches that could have been used?

This is an accepted approach. It is obvious that ongoing and extensive review and expansion (including this review) is required to evaluate the initial findings.

Question 2: Was the scope of this study appropriate? (consider geographical area, the breadth of services, goods and assets considered, and any others)

Yes. 
Question 3: Are the components of the framework (i.e. specific ecosystem services, goods, and assets) appropriate to this type of assessment in this region? Are there any that should be added or removed?

One important good has to be added in the assessment: power generation. Both hydro and coal based power generation depend on a constant water supply. During the recent 2001-2002 drought, a coal power plant needed to be shut down due to the lack of cooling water (Kienzle, 2006). This situation is likely to be exacerbated with climate change due to possible longer and more severe droughts.

Q Question 4: Is the level of detail shown in the conceptual diagram (page 32) sufficient to reveal the large-scale relationships between goods, services, and assets in Southern Alberta? Is this diagram useful?

Further, Figure 3-2 of the report shows conceptual linkages among assets, ecosystems services and goods. This figure is quite simplistic and its meaning is not clear, as no directions of linkages are provided, and potentially more classes (or percentages for better weighting) should be used. Although the Figure would become very complex, linkages to each of the elements of Assets, Goods and Services (e.g. Cereal crops, erosion control) should be established. Arrows should be added to show single- or bi-directional relationships. The links need to checked carefully: for example the link between Agriculture and Regulating Services: this should be a strong link, as farming practices have an impact on erosion and sediment transport.

- Question 5: Are these relationships sufficient to explain the role of EGS in southern Alberta? And, was the approach taken to modeling of these relationships useful? Are there any alternate approaches that you would suggest?

As discussed above, a major omission is that the relationships of assets on goods and services were not modelled.

Question 6: The analysis of the spreadsheets in the report was based on assigning a qualitative value of high, moderate or low importance between the two variables under consideration as described above. Assess the validity of this approach and the results.

As any evaluation that is based on classification, the fewer classes there are, the more general the approach. Three classes suggest a very general approach. Four, five, eight or 10 classes will allow a 
better evaluation and subsequent ranking, but will also get increasingly difficult to qualify. Three classes are acceptable for a very first rough evaluation, but more classes should be used for a complete assessment in the future.

Q Question 7: Section 4.5.I ranks the importance of ecosystem services to the production of goods. To complete this ranking the "basket of goods" that may be produced by each asset was determined. The importance of a given service to the production of each good was then averaged for all goods within an asset. This approach was taken to show the importance of services to goods within a summary table listing assets rather than goods. Is this approach easy for a reader to understand? Is there a better way to accomplish this analysis of importance of services to the production of goods?

No comment.

- Question 8: Do the rankings of services with respect to the function of maintaining assets (section 4.5.2) make sense based on your understanding of ecosystem services in southern Alberta? And, there is concern that the lower ranked services may be seen as unimportant by some who read this report. However, these services can be fundamental to the integrity of ecosystems in Alberta (e.g. Habitat/Refugia). Does the text of this report make this point clear, and with enough emphasis?

\section{Excel Spreadsheet: Workbook: Summary overall ranking}

It is interesting to see that Water Supply is ranked similar to Erosion control and sediment retention, and lower than Nutrient cycling. Erosion control and sediment retention is not a major and wide-spread issue in southern Alberta and should be ranked lower. And Nutrient cycling, while clearly essential, should not be ranked higher than Water supply, which has a major impact on Nutrient cycling. These few examples indicate that the spreadsheet evaluations need a careful revision, which would go well beyond the scope of this general review.

Question 9: The relative importance of ecosystem services is detailed in Appendix 9-7 to 9-26. This importance is based on four criteria: importance to the production of goods, importance to the maintenance of assets, importance at the margin, and the ability to manage an asset to provide the service. The knowledge of ecosystem service (column $\mathrm{G}$ ) was described in the table, but not factored into the overall ranking). Are these criteria appropriate to determining the importance of ecosystem services in southern Alberta? Are there any you would add? Should these criteria be equally weighted? And, the ability to manage an asset to provide a 
service was positively factored into the overall rank for a service. That is, the higher our ability to manage an asset for a given service, the more important the service would be ranked. There may be some merit in a different approach, in that our ability to manage an asset to provide a service is irrelevant to the overall importance of a service. In other words, if a service is important to producing goods and/or maintaining assets - its importance is not impacted by our ability to manage assets. Is it a good idea to factor in our ability to manage a service? Why or why not?

No comment.

Question 10: What are the logical next steps in continuation of this work?

See Recommendation at the end of this review.

Q Question 11: How do you see using this information in its current form being used to support environmental decision making, environmental management policy development and planning?

No comment.

Question 12: If we could make this information spatial, what questions would you suggest the maps attempt to answer?

\section{The need for more GIS integration}

An ecosystem can be defined as a geographically specified system of organisms (including humans), the environment, and the processes that control its dynamics. Any ecological good or service is spatially dependent on available ecological assets. In order to achieve the assessment of EG\&S, spatially dependent, multi-disciplinary, multi-scale and multi-temporal information needs to be integrated. Therefore, the use of existing and the establishment of new GIS databases and the development of spatial analyses procedures to qualify and quantify linkages between assets and goods and services is an approach that can add great value to an EG\&S assessment. For example, the Millennium Ecosystem Assessment Project based the development of indicators on remote sensing, image processing, spatial data bases, GIS technologies, coupled with modelling procedures (Heileman and MacDevette, 2002).

Not only are the individual assets, goods and services spatially distributed, but they also have different spatial relationships. Cumulative effects of assets, goods or services can be analyzed within a GIS framework. The evaluated importance of an asset, a good or a service can be mapped, and regions of higher importance can be distinguished from areas with less importance. 
For example, irrigated agriculture is dependent on water supply, soils, climate, and the infrastructure to provide water and move and process the produced product. All these are spatially limited, as most of the water used by the plants is provided from the mountains, the soils need to have a certain quality to provide water and nutrients to the plants, the climate varies spatially dramatically from southern Alberta's west to east, which, in turn, impacts the water demands. Further, the combination of soil and climate influences the optimum crops grown from these assets. The overlay and spatial analysis of all relevant layers can provide the water managers with information as to where the best crops can be grown with the least amount of water. Without spatial integration, this analysis is not possible.

While it would be a massive task to establish all major links between natural assets and goods and services, both between individual GIS layers and spatially, it could provide the basis for a transparent and repeatable EG\&S assessment. Further, the assets can be both quantified and qualified, thus allowing the impact analysis on the goods and services if one plans to change one asset (e.g. forest), or if one asset is undergoing a natural/unmanageable change on its own (e.g. climate change impact on snow pack and water supply).

The authors state under point 2.3 (Limitations of the Assessment) that there was no intent to incorporate any spatial analysis. Due to time limitations by the authors, the actual spatial analysis was prohibitive. However, as spatial analyses can have a profound impact on the assessment itself, the concept of spatial analysis should have been integrated in the assessment.

While the authors list the assets based on Alberta Environment's spatial database, no spatial analysis or spatial representation was provided (other than the asset percent areas in Figure 4-I), and neither ecosystem goods or services were analyzed spatially or mapped. As the authors state correctly, the asset condition can only be assessed when patch size, connectivity and configuration are considered, which, again, can only be analyzed using a GIS. A number of spatial analyses requirements are listed under Section 4.4, such as Natural Asset Patch Size, Contagion of Natural Assets, Linear Disturbance Density, or Boundaries and Edges. However, no attempt is made to show how this influences the asset condition.

The authors state under Gap \# 4 that more in-depth analysis of asset conditions is required. This statement should be extended much further, as ecosystem goods and services and their spatial linkage to ecosystem assets are essential for an EG\&S assessment.

A list of potential maps (general scale I : 250,000, but could vary) could include:

- Natural assets

- Current / future ecosystem services 
- Current / future ecosystem goods

- For each of the goods land services listed under point 4.3: distribution of goods/service, overlaid with natural and anthropogenic assets, e.g. livestock production, with linkages to natural assets (land base, food base, water courses, etc.) and anthropogenic assets (slaughter house, etc.)

- Relationships between assets and goods

- Relationships between assets and services

- Cumulative assessment of ecosystem services

- Cumulative assessment of ecosystem assets

- Many more as the project evolves

\section{Recommendations}

- The Phase 2 report is a good start, and it has identified many gaps already.

- Carry out an exhaustive literature review on EG\&S assessments, resulting in a gap analysis.

- Implement more than an economical view point: following ideas by Costanza (2000), add community driven and holistic view points in the overall assessment.

- Decide on a sub unit for the assessment. A combination of sub-watershed and county boundaries could be a good starting point. The benefit is that the assets, goods and services are likely to be both limited and unique in every unit, which makes the assessment much easier.

- As multi-source, multi-format, multi-scale spatial data need to be integrated, the establishment of a GIS database should be the preferred data depository, enabling critical spatial analyses.

- Organize workshops and conferences with very clearly defined objectives to bring together experts.

\section{References}

Barg S. and and Swanson D. 2004: Full Cost Accounting for Agriculture. International Institute for Sustainable Development, A paper written for Agriculture and Agri Food Canada (www.iisd.org/pdf/2006/measure_fca_2004.pdf)

Brown T.C., Bergstrom J,C, and Loomis J.B. 2006: Ecosystem Goods and Services: Definition, Valuation and Provision. RMRS-RWU-485I Discussion Paper.

http://www.fs.fed.us/rm/value/docs/ecosystem_goods_services.pdf 
Costanza, R., d'Arge, R. et al. 1997. The value of the world's ecosystem services and natural capital. Nature 387:253-260.

Costanza R. 2000: Social goals and the valuation of ecosystem services. Ecosystems (3), 4-10.

Daily, G.C., Soderqvist, T., Aniyar, S., Arrow, K., Dasgupta, P., Ehrlich, P.R., Folke, C., Jansson, A., Jansson, B., Kautsky, N., Levin, S., Lubchenco, J., Maler, K.G., Simpson, D., Starrett, D., Tilman, D., Walker, B. 2000. The value of nature and the nature of value. Science, 289(5478):395-396.

De Groot R.S., Wilson M.A. and Boumans R.M.J. (2002): A typology for the classification, description and valuation of ecosystem functions, goods and services. Ecological Economics 41: 393-408.

Duke G., Kienzle S.W., Johnson D. and Byrne J. 2003: Improving overland flow routing by incorporating ancillary road data into Digital Elevation Models. Journal of Spatial Hydrology, Vol. 3, No. 2, Fall 2003, 27pp.

Duke G., Kienzle S.W., Johnson D. and Byrne J. 2006: Incorporating ancillary data to refine anthropogenetically modified overland flow paths. Hydrological Processes, 20, 1827-1843.

Heileman S. and MacDevette D. 2002: Millennium Ecosystem Assessment Project - River Basin Assessments. Presentation for River Basin Information Systems Meeting, UNEP, Nairobi, I3-I4 February 2002.

Jewitt G. 200I: Can Integrated Water Resources Management sustain the provision of ecosystem goods and services? 2nd ARFSA/WaterNet Symposium: Integrated Water Resources Management: Theory, Practice, Cases; Cape Town, 30-31 October 2001

Kienzle S.W. 2006: The Use of the Recession Index as an Indicator for Streamflow Recovery After a Multi-Year Drought. Water Resources Management. 20, 991-1006. 


\section{EGS Review - Community-based Conservation \& Biodiversity Submitted by Dr. Kashif Sheikh}

I have undertaken this review to discuss the bigger picture of the importance of EGS in any given landscape; and how EGS coupled with valuation approaches may benefit conservation, sustainable use and economic diversification of the society.

\section{Abbreviations Used in the Text:}

EGS: Ecosystem Goods and Services

EA: Ecosystem Approach

CBD: Convention of Biological Diversity

CITES: Convention of International Trade in Endangered and Threatened Species

FNR: Foothills Natural Region

MA: Millennium Ecosystem Assessment

IUCN: The World Conservation Union

ABMP: Alberta Biodiversity Monitoring Program

ILM: Integrated Landscape Management

\section{Conserving Biodiversity and Ecosystem Services:}

CBD is considered the mother of biodiversity conservation and sustainable use agenda in the world. It has a huge emphasis on ecosystem approach and landscape management at the ecosystem level. Article 2 of the Convention of Biological Diversity (CBD) defines;

\section{Ecosystem" as a dynamic complex of plant, animal and micro-organism communities and their non-living environment interacting as a functional unit".}

(Article 2 of the CBD)

At the international level, the importance of biodiversity and ecosystem services to human wellbeing has been enshrined in the text of several multilateral environmental agreements. For example, the preamble to the Convention on Biological Diversity (CBD) notes "the intrinsic value of biological diversity and of the ecological, genetic, social, economic, scientific, educational, cultural, recreational and aesthetic values of biological diversity and its components". The Convention on International Trade in Endangered Species of Wild Fauna and Flora (CITES) is "Conscious of the ever-growing value of wild fauna and flora from aesthetic, scientific, cultural, recreational and economic points of view". 


\section{Fundamentals of EGS in any Given Landscape:}

The ecosystem approach is a strategy for the integrated management of land, water and living resources that promotes conservation and sustainable use in an equitable way. Application of the ecosystem approach will help to reach a balance of the three objectives of the CBD. It is based on the application of appropriate scientific methodologies focused on levels of biological organization which encompass the essential processes, functions and interactions among organisms and their environment. It recognizes that humans, with their cultural diversity, are an integral component of ecosystems. Keeping these facts in mind, we need an integrated approach to science that gets the public involved in collecting data and discussing the significance of findings before advice goes to the policy and decision makers. Integration of public or key stakeholders provides key insights of the functioning and limitation of an ecosystem and would likely put the assessment processes many steps ahead. In summary, an integrated EGS assessment may ensure:

- Wider stakeholder involvement helps to generate long-term effective partnerships, effective conservation decision-making for the long-term sustainability of the wild resources.

- No compromise on species/ habitats and ecosystems declared threatened and or endangered.

- Appropriate spatial analysis of all components and levels of an ecosystem.

- Economic Valuation of the major Assets, Goods and Services generated from the subject ecosystem.

- Reasonable linkages with Public Policy dialogues and Environmental friendly business/trade for effective but sustainable environmental decision making.

\section{How Much is an Ecosystem Worth:}

Ecosystems provide a wide variety of useful services that enhance human well-being. Without these services, we would be worse off in many ways. At the limit, we may not survive. But even degradation of ecosystem services falling well short of outright destruction would significantly affect our welfare. It has often been argued that a major reason for our failure to conserve natural ecosystems is that we do not realize how valuable they are. The farmers deciding whether to burn a hectare of forest to clear it for agriculture focus on the potential crop yields they may obtain, but pay little attention to the many ecological services that would go up in smoke. Likewise, national ministers of finance often base their budget decisions solely on the basis of indicators such as GDP, foreign exchange balances, and tax receipts, in which ecosystems services either do not appear or are not recognized as such-indeed, perversely, GDP often identifies activities that destroy ecosystems as 'benefits'. Not surprisingly, conservation budgets tend to get slighted (IUCN, The Nature Conservancy and The World Bank, 2004).

\section{Ecosystem Goods and Services (EGS) Defined:}

Ecosystem services are defined as "the benefits of nature to households, communities, and economies." The term has gained currency because it conveys an important idea: that ecosystems are socially 
valuable and in ways that may not be immediately intuited (Daily 1997). I chose this definition, because it shows a holistic move towards the nature and society linkage.

Why do we Need to Understand EGS, and Bring Costs and Economic Valuation into EGS? Ecosystems and biodiversity provide a wide range of services through their bio-geo-chemical processes that are critical for sustenance of humans. An ecosystem, which is a dynamic complex of plant, animal and micro-organism communities and other non-living environmental components interacting as a functional unit, provides services which sustain, strengthen and enrich various constituents of human well-being. Human well-being here refers to a wholesome set of basic material for a good life, freedom to act and make choices, good social relations, and security (MA, 2003). The unique feature of most of the services emanating from ecosystems is that although acknowledged by people, they are unaccounted, unpriced and therefore remain outside the domain of the market. In conventional phrasing, such problems are treated as externalities where the market fails, and decision-makers try to correct the market failure by creating a market-like situation. Subsequently they obtain the value of services through various valuation techniques based on the stated preferences of the people. In the case of the regulating services of ecosystems, like climate regulation, waste treatment capacity, nutrient management and various watershed functions, classic examples of market failure appears (Bator, 1958).

Economic valuation is one of the tools we can use to assess the benefits of ecosystem conservation as well as how these benefits are distributed among the stakeholders. Through an analysis of benefits and costs, we can begin to understand some of the forces which may be threatening the existence of the ecosystem. A major threat to conserving ecosystems, including forest, savannah and wetland systems, is the demand to use the land for agricultural or ranching purposes (Vorhies, 2003).

By recognizing the benefits and costs facing local communities from conserving the ecosystem, we will be able to reduce the pressures and boost the substantial returns to the production of ecosystem conservation.

\section{Purpose of EGS in Southern Alberta:}

The overall purpose of this project is to identify 'what EGS are important to southern Alberta and how they are key in sustaining the region's vibrant economy and quality of life' (Page 3 of EGS Final Report). The EGS assessment will feed into the Southern Alberta Landscapes (SAL) regional strategy. 


\section{Objectives of the EGS Assessments in southern Alberta as they are:}

- Inform people about ecosystem goods and services and how they are important to economic production in southern Alberta,

- Help people understand how land use decisions and human activities impact these services.

- Determine what landscape patterns are required to sustain the ongoing delivery of ecosystem goods and services.

- Undertake a gap analysis to identify directions for further study and investigation.

\section{Analysis of the key questions:}

Five questions provided in the EGS assessment (page I) guided the current EGS assessments. I reviewed them all and developed the following analysis:

Ecosystems are the storehouses of primary and secondary resources to provide various functions and services in delivering various goods to the nature and humanity. The first question should probably read as how ecosystems assets such as forests, wetlands, mountains maintain the services for providing various goods, though this relationship is inter-related; the assets produce goods through the route of various services. Again, if we carefully analyse question 4 then it underlines the same need; how the condition of natural assets affect the quality and quantity of the services they offer. Question 3 demands a careful analysis of how anthropogenic factors/assets limit or expand the effectiveness of the ecosystem services and how in turn this affects the natural assets in delivering the goods. One can draw from question 3 that a breakdown analysis of the various changes brought by man-made or man-induced factors would be undertaken to understand the up-to-date significance of the natural assets.

\section{Ultimate Goal of the EGS for Southern Alberta: (My view)}

The ultimate goal of an EGS for southern Alberta may ideally look to;

'Offer a strategic substitute technique for the conservation and sustainable use of the wild resources in southern Alberta, with improved enabling natural resource policies, but without compromising the needs of the human well-being and without disturbing the complex balance of natural systems.'

\section{General Comments on the EGS Report:}

The main purpose and key objectives of the EGS assessment is to add value to the lively economy; and educate people as to how EGS knowledge would help improve the economic production and decision making in southern Alberta. However, the report clarifies that it hasn't undertaken any valuation or study of the market or non-market based benefits associated with EGS. 
- Authors mentioned that EGS would contribute to the SAL; however, the report lacks the necessary connection here. Ideally a brief summary should be provided on SAL and then how EGS fills in the gaps within SAL.

- Protected Areas (PAs) are not discussed as they should be in this case. Southern Alberta has lots of leading PAs that needs to be given due consideration and assessment because most of the Environmental services are obviously noticed there. There are noticeable means and opportunities to investigate in protected areas because of effective control, liaison and organization of the protected environment and resources. EGS approaches could be well defined there and later they can be replicated in other areas.

- Biodiversity is wide and an interrelated term. It stands at the level of an asset and may also serve as a good due to the various services it performs by the ecosystems. It maintains the basis of the various assets. Forest, grasslands, prairies and aquatic systems are all key components of biodiversity. It may be recommended that biodiversity can't just be regarded as a good coming out of the ecosystem processes.

- Authors briefly touched on the impact of expansion of anthropogenic assets on the ecosystem services. It is very general and may not be enough. It may be useful to conduct a quantitative analysis of the impact of certain anthropogenic factor and then measure the effectiveness of the services/ assets. This way it becomes more meaningul and practical to implement the plans. We probably need to avoid text book approaches and create or discuss examples from the real-life scenarios. Imagine if an ecosystem planner has to evaluate how the growing housing development in the Foothills Natural Region (FNR) is making a huge or small impact on the functioning of the ecosystems services/ assets. How he is going to learn from the analysis provided here as well as the picture 4-I. The assessment should aim at proving a guideline and set of tools to achieve this purpose.

\section{Specific Comments:}

\section{Key Questions and Answers:}

- Evaluate the overall framework developed to highlight the relationships between the goods, services and assets and rank the importance of ecosystem services in southern Alberta.

The assets support the maintenance of the services through various direct and indirect relationships. In principle this should be the way of leading into the details of the report. 
Review the relationships (excel spreadsheets) between the goods, services and assets and flag areas of perceived discrepancy (provide reasoning).

The relationships are useful but look more narrative and fall short of an analytical touch. Within the spreadsheets, just mentioning that cultural services have positive relationships with aquatic assets does not mean much. This needs to be analyzed preferably through examples. If we are able to demonstrate how a cultural service is well represented in the aquatic ecosystem then the reader or manager can use that understanding to define his personal approach in mitigating threats and opportunities in such aquatic ecosystem. A better approach to examine this relationship may be ranking in numbers or using a standard formula in assessing the importance of an asset in maintaining a service.

- Offer additional perspective, opinion and recommendations related to topics they feel are of importance.

It seems real life scenarios are missing or lacking from the report. One of the objectives of the report is to determine the spatial pattern of the landscapes that should remain relatively undisturbed in Alberta in order to sustain the delivery of EGS. This point is not really emerging from the report. Ideally the conditions of several or selected ecosystems in southern Alberta should be discussed in the real-life and mitigation measures may be suggested to sustain the delivery of EGS.

It is very important to understand why Southern Alberta needs EGS. What is different in this EGS approach that is not addressed in other similar programs such as ABMP, ILM etc? Another overarching question is if the new approach is justified how does this EGS approach add value to existing approaches?

Valuation of the EGS is important in the first place. Particularly, examining how the costs and benefits of an ecosystem are distributed; different stakeholder groups often perceive very different costs and benefits from ecosystems. Understanding the magnitude and mix of net benefits received by particular groups is important for two reasons. From a practical perspective, groups that stand to 'lose' from conservation may seek to undermine it. Understanding which groups are motivated to conserve or destroy an ecosystem, and why, can help to design more effective conservation approaches. From an equity perspective, the impact of conservation on particular groups such as the poor, or indigenous peoples, is also often of significant concern in and of itself. 


\section{Key questions put forth by AENV and the consultants who completed the EGS assessment:}

- Question 1: The approach used to determine the importance of, and relationships between, goods, services, and assets was based on professional opinion. This was done by consensus in a team of five professionals consisting of environmental landscape planning experts. Was this approach appropriate for this study? Are there alternate approaches that could have been used?

Ecosystems provide a wide variety of useful services that enhance human well-being. The Ecosystem Approach (EA) places human needs at the centre of biodiversity management. It aims to manage the ecosystem, based on the multiple functions that ecosystems perform and the multiple uses that are made of these functions. The ecosystem approach does not aim for short-term economic gains, but aims to optimize the use of an ecosystem without damaging it. With this background, any EGS assessment would require a multi-disciplinary approach. EGS Assessment and a planning team must include ecosystem management experts, conservation economists and biologists, biodiversity planners, water resource experts, landscape and geography personnel. We need an integrated ecosystem approach to science that gets the public involved in collecting data and in discussing the significance of findings before advice goes to the policy and decision makers. Ideally EGS should have wider participation of the diverse stakeholders and contributors at the planning stage because many sectors of society would benefit or be disadvantaged from the results of EGS. In the beginning of the EGS assessment, report authors may want to provide a synopsis of the various worldwide EGS approaches and then justify this approach as a priority choice for southern Alberta.

Question 2: Was the scope of this study appropriate? (consider geographical area, the breadth of services, goods and assets considered, and any others)

In general, it is a good starting point and provides a good planning tool for further design of on-ground EGS evaluations. If we refer to the section on Limitations to the Assessments, it underlines various important parameters which are probably not considered due to time limitations. If the assessment team realizes that more experts need to be involved then that is the way to go. Most of the information with regard to the impact of the anthropogenic factors is very general or rather relative. Even if it was not possible to collect information for the whole of southern Alberta, it may be possible to do some pilot assessments involving detailed analysis of anthropogenic impacts on a certain ecosystem type to show the relative linkages and aftermaths. For example for presentation purposes; text boxes may be added for a specific ecosystem in the Rockies and EGS elaborated around it for clarity sake. An in-depth study of various parameters is required for any given area, preferably with good field data collected for the purpose of EGS assessments. 
Also, decision-makers need objective technical assistance to identify the opportunity and risks of using different types of market instruments for ecosystem services and for designing them to be effective, efficient and equitable (Kumar, 2005).

Question 3: Are the components of the framework (i.e. specific ecosystem services, goods, and assets) appropriate to this type of assessment in this region? Are there any that should be added or removed?

The human linkages with the whole ecosystem are not apparent from this assessment.

- Question 4: Is the level of detail shown in the conceptual diagram (page 32) sufficient to reveal the large-scale relationships between goods, services, and assets in Southern Alberta? Is this diagram useful?

This diagram is useful but more explicit and user-friendly information needs to be integrated. One option would be to use real-life language/words from within the working systems. Managers, researchers and policy makers are prone to those institutional working words on daily basis. This would help in saving time and achieving simplistic understanding.

- Question 5: Are these relationships sufficient to explain the role of EGS in southern Alberta? And, was the approach taken to modeling of these relationships useful? Are there any alternate approaches that you would suggest?

No comment.

Question 6: The analysis of the spreadsheets in the report was based on assigning a qualitative value of high, moderate or low importance between the two variables under consideration as described above. Assess the validity of this approach and the results.

The approach seems broad. This can be improved for practical understanding and use. It may be valuable to give examples of real-life ecosystem and or habitat types and relate their EGS importance accordingly. In that way, we can demonstrate how a certain Service or Good is more important than others. I would like to re-emphasize the points raised in the gap- analysis which is given under the Key Findings in this report. 
The report seems theoretical from the user point of view. It may serve as broad guideline, and I think. resource managers may need to start from step one and would still need to start making linkages for his or her own ecosystem problems and integrating various critical parameters.

- Question 7: Section 4.5.1 ranks the importance of ecosystem services to the production of goods. To complete this ranking the "basket of goods" that may be produced by each asset was determined. The importance of a given service to the production of each good was then averaged for all goods within an asset. This approach was taken to show the importance of services to goods within a summary table listing assets rather than goods. Is this approach easy for a reader to understand? Is there a better way to accomplish this analysis of importance of services to the production of goods?

This is good as a starting point and provides a model, however, it may be useful to take a few examples from the rest of the world and make linkages in southern Alberta so that a manager could visualize the importance of Services to Goods and Goods to Services.

Q Question 8: Do the rankings of services with respect to the function of maintaining assets (section 4.5.2) make sense based on your understanding of ecosystem services in southern Alberta? And, there is concern that the lower ranked services may be seen as unimportant by some who read this report. However, these services can be fundamental to the integrity of ecosystems in Alberta (e.g. Habitat/Refugia). Does the text of this report make this point clear. and with enough emphasis?

It is good start to rank the service with respect to the functions of maintaining an asset or vice versa. However, it may be useful to value goods and services first in the socio-economic and pure economical angle. However, people perceive services in various different ways with respect to the functioning or maintenance of an asset. Indigenous human populations have diverse uses and relationships with the ecosystems and their goods. In fact there are multi-dimensional benefits or uses that are drawn from one asset. For example in a mountain ecosystem people use a certain plant or a community of plants for protecting their backyards, making an enclosure for their livestock and burning it as a fuel; however, the same plant community may be used by birds as a breeding habitat and nesting territory and it may be naturally serving the river in protecting its edges from widening (Sheikh, et al 2002). So there are several users of the same asset which is offering a variety of services.

Q Question 9: The relative importance of ecosystem services is detailed in Appendix 9-7 to 9-26. This importance is based on four criteria: importance to the production of goods, importance to the maintenance of assets, importance at the margin, and the ability to manage an asset to provide the service. The knowledge of ecosystem service (column G) was described in the 
table, but not factored into the overall ranking). Are these criteria appropriate to determining the importance of ecosystem services in southern Alberta? Are there any you would add? Should these criteria be equally weighted? And, the ability to manage an asset to provide a service was positively factored into the overall rank for a service. That is, the higher our ability to manage an asset for a given service, the more important the service would be ranked. There may be some merit in a different approach, in that our ability to manage an asset to provide a service is irrelevant to the overall importance of a service. In other words, if a service is important to producing goods and/or maintaining assets - its importance is not impacted by our ability to manage assets. Is it a good idea to factor in our ability to manage a service? Why or why not?

Please consider these points for managing a service:

- Specific sources of ecosystem services need to be identified for proper valuation.

- Need to develop payment mechanisms, and identify buyers and sellers of ecosystem services.

- Necessary to identify the potential of the returns of EGS to enhance livelihoods, particularly for socially and economically disadvantaged groups.

Question 10: What are the logical next steps in continuation of this work?

- To do public/ stakeholder consultations.

- To integrate economic angle for a better understanding of the issues and opportunities.

- Extensive reviews of the EGS approaches worldwide.

- Launching of a pilot scale EGS evaluation exercise at a watershed level or a major well-known ecosystem type in southern Alberta.

- Engage environmental ministries and agencies in promoting the role and value of ecosystem services in economic development including in the context of international economic and biodiversity agreements.

- Raise awareness within administrations of all sectors at the provincial level with respect to the role of ecosystem services in delivering their development objectives.

- Promote legislative frameworks and voluntary initiatives that enable markets for ecosystem services including markets for carbon emission reduction and sequestration, watershed management, and biodiversity conservation and promote true valuation of ecosystem services, including removal of subsidies and perverse incentives.

- Complete a gap analysis of ecosystem coverage by protected areas to identify key opportunities for protected areas that can enhance local livelihoods. 
- Enhance management effectiveness of protected areas to improve delivery of ecosystem services provided by those areas.

a Question 11: How do you see using this information in its current form being used to support environmental decision making, environmental management policy development and planning?

In my opinion, it would be difficult for the managers and decision makers to use the information as such. This needs to be simplified. They need to understand that ecosystem valuation is important so that they can weigh the importance of EGS and act accordingly.

Q Question 12: If we could make this information spatial, what questions would you suggest the maps attempt to answer?

The real task is how GIS integration can simplify this job in making management/decisions and data presentation look better.

\section{Comments on the GAP Analysis: (Page 85 onwards)}

Item 5, 6 and 7 should not be kept on low or medium priority and rather should be the high priority. For example, item 7 would probably serve as a strong basis of any practical EGS worldwide. It should further involve exchange of ideas at the time of the valuation of the ecosystems with the policy and decision makers who are ultimately going to be the users/ managers of the information and progress of the EGS assessments. If EGS assessments are conducted in isolation from the other key stakeholders then they are likely to be less winning. Public consultation and sharing is as important as is the management/ implementation of the EGS assessment. The Ecosystem Approach places human needs and interests at the centre of biodiversity management. It aims to manage the ecosystem, based on the multiple functions that ecosystems perform and the multiple uses that are made of these functions. The ecosystem approach does not aim for short-term economic gains, but aims to optimize the use of an ecosystem without damaging it.

I understand that the GAP analysis presents the most important points that were somehow not integrated into the EGS assessment approach. However, it is not clear why one or all of these points could not be integrated at the time of current assessment. Public consultation and involvement as well as EGS design in line with policy development are one of the key essentials if an EGS approach has to bring positive change and value to the existing approaches. 


\section{Management Challenges of the current EGS:}

I foresee few management challenges arising from the current approach of the EGS and its presentation.

The question remains as to how an environmental manager would use the information from this EGS report (as it is) to improve his ecosystem management strategies. How will a biodiversity planner or ecosystem resource manager use this information to protect or sustain his wild jurisdictions? A lot would need to be done along the way. The theoretical ranking and analyses should be transferred first in the form of flow charts and practical examples taken from the respective areas where the EGS recommendations should work. If the ecosystem or biodiversity conservation planner of the Banff National park is to improve conservation and sustainable use (based on EGS assessment approach) in his park, how would he use the information and guidelines in the current EGS assessment? For example, in economics language it may be uncomplicated to say that ground level data on producer costs for managing ecosystem services, markets, operational costs and the costs of establishing and operating different types of market instruments must be collected, synthesizes and analyzed before saying anything useful on the functioning of markets for ecosystem services. If this is right, how can that planner decide for his park? Ideally various prime habitat/ ecosystems of southern Alberta should be listed first and EGS should be applied on those ecosystems while modelling the various elements of the existing nature and society linkages.

\section{How Can this Program become more Meaningful:}

If the EGS was conducted using the valuation for various goods, services and assets; and it involved key stakeholders from real-life then it becomes much more meaningful to implement results in various dimensions. Ideally, EGS approaches should strengthen markets for ecosystem services, and identify new ones, in which companies can profitably invest for increasing value for their shareholders while enhancing their contribution to community development and nature conservation. Experience shows that creating market incentives for ecosystem services is possible, but not simple. It may require sound science to document the volume, value and costs of providing ecosystem services, under alternative management regimes as well as political will and/or institutional commitment to establish payment and trading regimes for ecosystem services, whether on a voluntary basis, under local or national law, or as part of international agreements; and institutional innovation to create viable business models as well as credible processes for monitoring, evaluation and public accountability. Further;

\section{Integrate Biodiversity Language into this report:}

Biodiversity can be interpreted as a form of natural insurance for risk averse ecosystem managers against the over or under-provision with ecosystem services, such as biomass production, control of water run-off, pollination, control of pests and diseases, nitrogen fixation, soil regeneration etc. Thus, 
biodiversity has an insurance value, which is a value component in addition to the usual value arguments (such as direct or indirect use or non-use values, or existence values) holding in a world of certainty. This insurance value should be taken into account when deciding upon how much to invest into biodiversity protection. It leads to choosing a higher level of biodiversity than without taking the insurance value into account, with a higher degree of risk aversion leading to a higher optimal level of biodiversity (Baumgartner, 2005). As far as the insurance function is concerned, biodiversity and financial insurance against income risk, such as crop yield insurance, may be seen as substitutes. If financial insurance is available, a risk averse ecosystem manager, say, a farmer, will partially or fully substitute biodiversity's insurance function by financial insurance, with the extent of substitution depending on the costs of financial insurance. Hence, the availability, and exact institutional design, of financial insurance influence the level of biodiversity protection.

Biodiversity science and protected areas systems are one of the most acceptable ways of understanding natural set ups, however, it is felt that biodiversity science language, protected areas opportunities and their importance have not been fully realized in the EGS report as much as it could have been.

\section{Increasing Investment in Ecosystem Services for People:}

Good landscape management will fulfill societal needs by equitably balancing trade-offs between the productive, social and environmental requirements of current land use. To function properly it requires supportive policies, incentives and institutions that are capable of operating at that scale. It means conserving and restoring ecosystems so that they can fulfill their potential to support livelihoods. It means ensuring the concerns of people depending on those ecosystems are taken into consideration when decisions are taken. It also means incorporating the understanding of how a management action in one part of the landscape may impact another and allowing flexibility and adaptation in management responses for changing situations (Raju et al, 2007). Building on these three key challenges, and employing the key strategies of partnerships and knowledge mobilisation, a suite of more specific approaches is suggested as fundamental to success. A change in behaviour is needed. The political will for change is a necessary foundation for achieving success.

The concept of payments for ecosystem services is being developed as an important means of providing a more diverse flow of benefits to people living in and around habitats valuable for conservation. The Kyoto Protocol, under the United Nations Framework Convention on Climate Change, includes a Clean Development Mechanism to provide payments for certain forms of carbon sequestration that may benefit wildlife (at least as an incidental benefit). Other market-based approaches for paying for carbon sequestration services outside the Kyoto framework are being promoted in various parts of the world. Another common form of payment for ecosystem services is compensating upstream landowners for managing their land in ways that maintain downstream water quality; this can include habitat management that benefits wildlife. While biodiversity itself is difficult to value, it can be linked to 
other markets, such as certification in the case of sustainably-produced forest products (McNeely, 2007).

\section{Explore and support payments for ecosystem services}

The Millennium Ecosystem Assessment has provided a comprehensive overview of the ecosystem services upon which humans depend. Many of these services have been shown to have significant economic value in terms of their contributions to production and consumption (NRC, 2004). Yet, most ecosystem services remain virtually free-of-charge at the point of use. Where supplies of ecosystem services are plentiful, relative to human demand, the lack of a price or some other mechanism to ration their use poses little problem. Increasingly, however, the growing demand for ecosystem services combined with external pressures on the ecosystems that provide them have led to scarcity, congestion, conflict and growing risks to human wellbeing. In this context, the continuing failure of markets to charge for the use of ecosystem services (or to reward the provision of ecosystem services) has become an increasingly severe constraint on long-term economic performance and sustainable development. While most ecosystem services are not traded in markets, there are important exceptions.

\section{Discussion:}

The direct causes of biodiversity loss include habitat destruction, over-exploitation, pollution and invasive species. Behind these proximate causes lies a rapidly globalizing economic system, increasingly driven by international trade and private investment. Sustainable development cannot be achieved in isolation from ensuring economic wellbeing, equity, environmental health and addressing social development goals. However, the current reality is that efforts to achieve sustainable development have tended to put most emphasis on economic development, often at the expense of social and environmental factors. But the goods and services that drive our economy and support our social systems stem largely from a healthy functioning environment. IUCN calls for the three pillars of sustainable development to be more equitably balanced by integrating environmental concerns into economic and social development thinking (Mainka, S. et al 2005). A number of key national planning processes have been conducted over the last several years to establish national investment priorities to ensure environmental sustainability. Some of the more intractable problems facing ecosystems and threatening livelihoods are those of climate change and invasive alien species. An integrated approach to these issues will be essential to success.

\section{Conclusion/ Recommendations:}

- Holistic (Nature-Society-Economy) approach needs to be integrated.

- Ideally, any EGS approach should involve a diverse set of stakeholders, interest groups, stewardship activists, planners, scientists and conservationists over several months or couple of years to decide the natural, economical and anthropogenic basis of various goods, services, assets and linking them 
with market mechanisms to evaluate the linkages, dos and don'ts and what may or may not work in the real-life.

- Clear and easily comprehensible documentation of the biophysical linkages between land uses and ecosystem service benefits, forest conservation and enhanced watershed services, conservation territorial and aquatic biodiversity and corresponding benefits, carbon parking and related marketed benefits along with appropriate methods for measuring and monitoring the provision of services, would go a long way in making the market work for ecosystem services.

- Other EGS approaches need to be reviewed and integrated firsthand from worldwide resources. Some readings and resources are suggested in the following section.

- Make information and maps practical for people who are going to implement the tasks. The manager would need to digest a language and an approach to understand how to implement it.

- The ultimate goal is to provide a better insight of the natural resources and their worth in southern Alberta but does the current information flow suitably for decision makers who could make betterinformed decisions?

- Analysis for the site-specific design of market rules and institutions are still in the rudimentary stage and there exists a considerable amount of knowledge gaps on this. In order to make it amenable for macro-analysis careful synthesis of findings would be critically needed.

- It may be useful to consider a pilot scale EGS approach since that may provide clear consequential results and strategies on ground. Data may also be collected and coordination may be more effective with all sectors of society.

- Capacity building to develop national sophisticated expertise in analyzing, designing and implementing ecosystem service markets in the public, private and civic sectors is needed at all levels and probably in every part of the world.

- There must be opportunities to exchange experiences, perspectives and lessons about the use and design of ecosystem service markets with peers in other countries and regions are also very much desirable.

\section{Suggested Readings/ Resources for the EGS Authors:}

Boyd, J., and Banzhaf. S., (2006). What Are Ecosystem Services?. The Need for Standardized Environmental Accounting Units. Resources for the Future, 1616 P St. NW Washington, DC 20036 202-328-5000.

Emerton L, Bos E (2004). Value: Counting Ecosystems as Water Infrastructure. IUCN. Gland, Switzerland.

McNeely, J.A., (2007). A zoological perspective on payments for ecosystem services. Integrative Zoology 2:68-78. 
Sagoff, M., (1997). Can We Put a Price on Nature's Services? Philosophy and Public Policy 17(3): 7-12.

Stefano, P., et al. (2004), Assessing the Economic Value of Ecosystem Conservation, TNCIUCN-WB, Washington DC.

Stevens, C., Scrimgeour, G., Tonn, W., Paszkowski, C., Sullivan, M., and Millar, S., (2006).

Development and testing of a fish-based index of biological integrity to quantify the health of grassland streams in Alberta. Technical report (T-2006-00I) produced by Alberta Conservation Association, Edmonton, Alberta, Canada. 50 pp + App.

Economic Valuation of Mangrove Ecosystems: Potential and Limitations

http://www.biodiversityeconomics.org/applications/library documents/lib_document.rm?document_id=758

BIODIVERSITY CONSERVATION - Making the Link with Business Environmental Responsibility and Leadership Corporate Strategies

http:/www.biodiversityeconomics.org/applications/library documents/lib document.rm?document id=226

Economic Valuation of Coral Reefs in the Caribbean available at

http://pdf.wri.org/methodology with_appendix jul06.pdf

\section{A TYPOLOGY FOR THE CLASSIFICATION, DESCRIPTION AND VALUATION OF ECOSYSTEM FUNCTIONS, GOODS AND SERVICES}

http:/www.iucn.org/themes/cem/documents/eservices/ecosystem typology degroot.pdf

Asia Regional Workshop on Compensation for Ecosystem Services: A Component of the Global Scoping Study on Compensation of Ecosystem Services

http:/www.worldagroforestrycentre.org/downloads/publications/PDFs/WP 14957.PDF

\section{References:}

Bator, F. M., (1958). "Anatomy of Market Failure," Quarterly Journal of Economics, 72:3 (August), 35I-379.

Baumgartner, S., (2005). The Insurance Value of Biodiversity in the Provision of Ecosystem Services. Department of Economics, University of Heidelberg, Germany

Daily, G., (1997). Nature's Services: Societal Dependence on Natural Ecosystems. Washington, DC: Island Press. IUCN, The Nature Conservancy and The World Bank., (2004). How Much is an Ecosystem Worth?, The World Bank, Washington DC.

Kumar, P. (2005). Market for Ecosystem Services. International Institute for Sustainable Development (IISD). International Institute for Sustainable Development 161 Portage Avenue East, 6th Floor Winnipeg, Manitoba. 32 pp. 
Mainka, S., McNeely, J., and Jackson B., (2005). Depend on Nature. Ecosystem Services supporting Human Livelihoods. IUCN - The World Conservation Union, Rue Mauverney 28, 1196 Gland, Switzerland.

MA (Millennium Ecosystem Assessment)., (2003). Ecosystems and Human well being. Island Press: Washington DC.

McNeely, J.A., (2007). A zoological perspective on payments for ecosystem services. Integrative Zoology 2:68-78.

National Research Council. (2004). Valuing Ecosystem Services: Toward Better Environmental Decision-Making. Washington DC: National Academy of Sciences.

Raju K.V., S. Puttaswamaiah and Rumley R., (2007). Asia Regional Workshop on Compensation for Ecosystem Services. A Component of the Global Scoping Study on Compensation of Ecosystem Services ICRAF Working Paper no. 34. Nairobi: World Agroforestry Centre.

Sheikh, K.M., Ahmad, T., and Khan M. A., (2002). Use, Exploitation and Prospects for conservation: People and Plant Biodiversity of NW Karakorums, Pakistan. Biodiversity \& Conservation.

Vorhies, F. (2003). Environmental Economics Explained. IUCN-The World Conservation Union, Gland Switzerland.

\section{Web Resources:}

www.iucn.org/ecosystems

http://www.biodiversityeconomics.org

www.biodiv.org

www.idrc.ca

http://www.wri.org/biodiv/pubs_description.cfm?pid=3813

http://www.iisd.org/ 


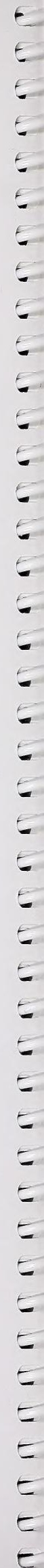



) 